\title{
Total Synthesis of (-)-Spinosyn A: Examination of Structural Features that Govern the Stereoselectivity of the Key Transannular Diels-Alder Reaction
}

\author{
SusAnn M. Winbush, ${ }^{a}$ Dustin J. Mergott, ${ }^{b \dagger}$ and William R. Roush ${ }^{a *}$ \\ ${ }^{a}$ Department of Chemistry, Scripps Florida, Jupiter, Florida 33458; ${ }^{b}$ Department of \\ Chemistry, University of Michigan, Ann Arbor, Michigan 48105
}

roush@scripps.edu

Supporting Information:

Part II. ${ }^{1} \mathrm{H}$ and ${ }^{13} \mathrm{C}$ NMR Spectra of Key Compounds

All compounds with "SI" numbers are depicted in the Supporting Information, but not in the manuscript text. 


\section{Table of Contents:}

\section{${ }^{1} \mathrm{H}$ and ${ }^{13} \mathrm{C}$ NMR Spectra:}

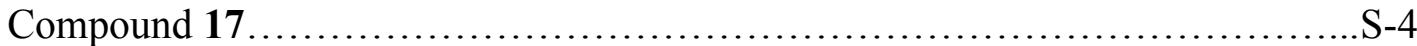

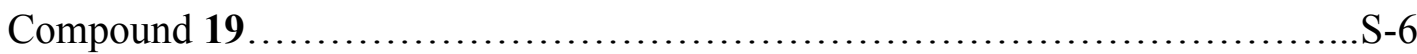

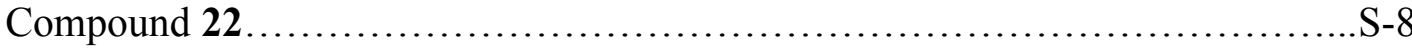

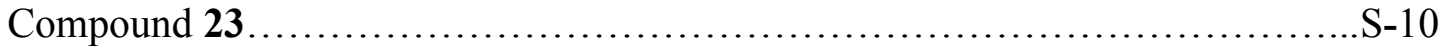

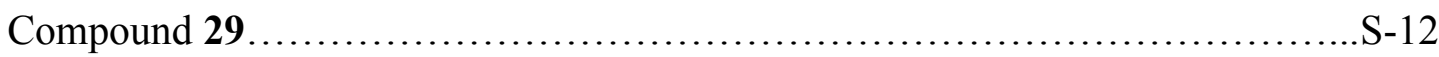

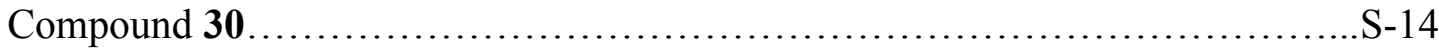

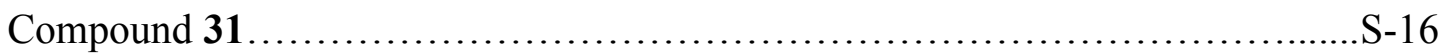

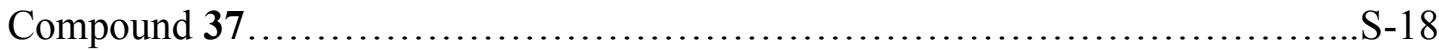

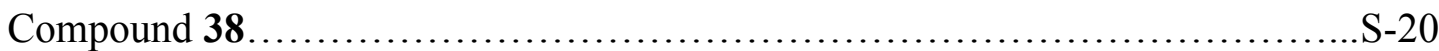

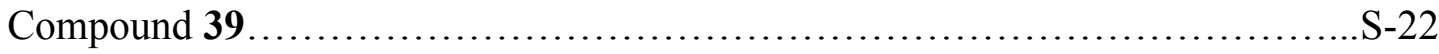

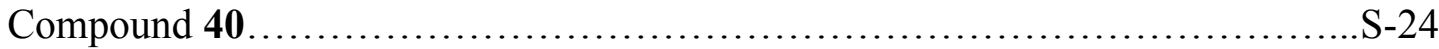

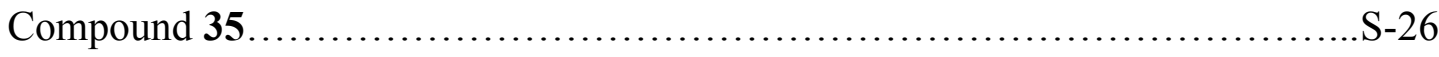

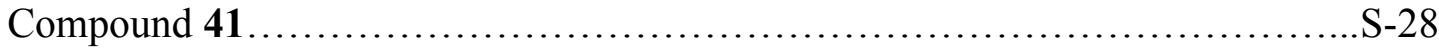

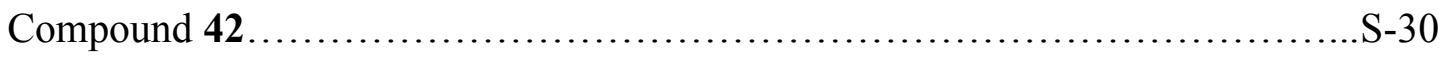

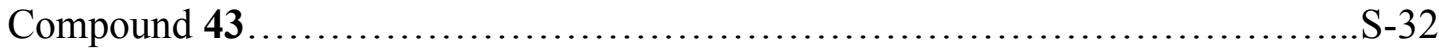

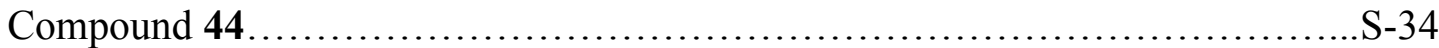

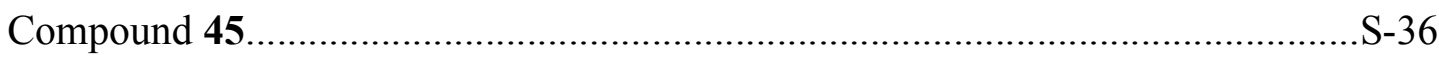

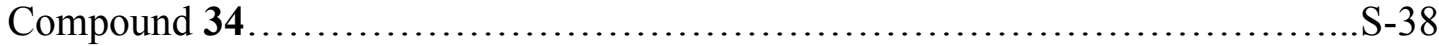

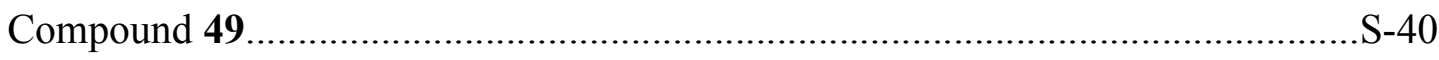

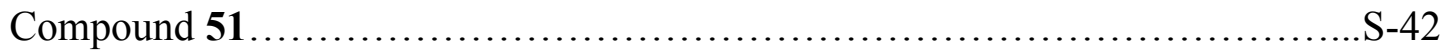

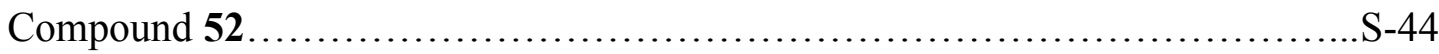




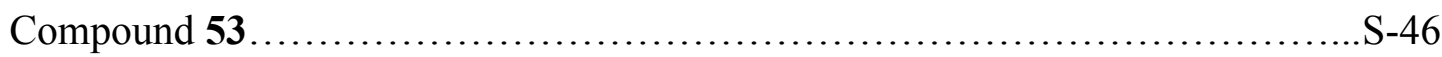

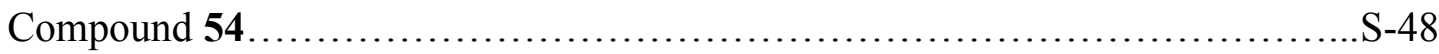

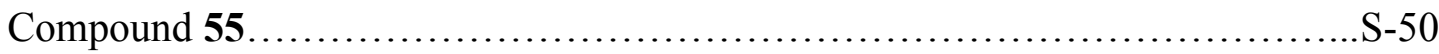

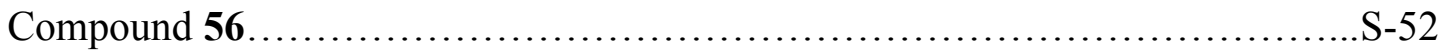

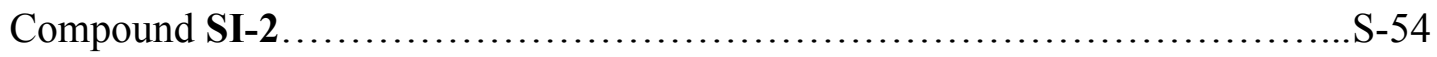

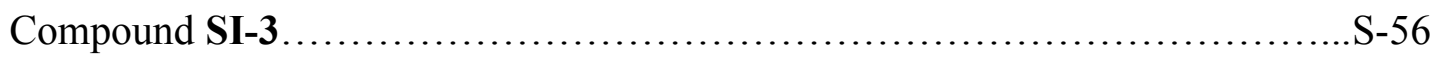

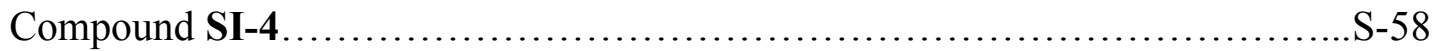

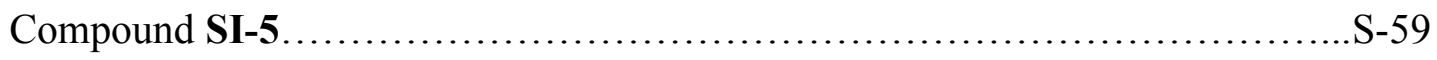

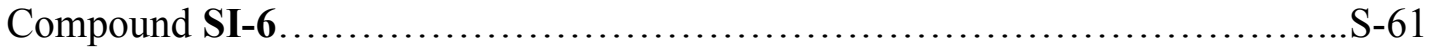

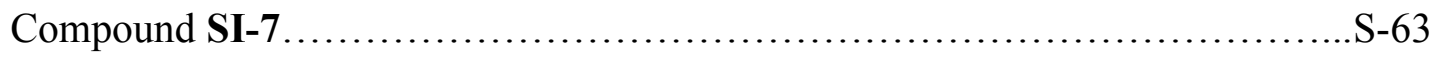

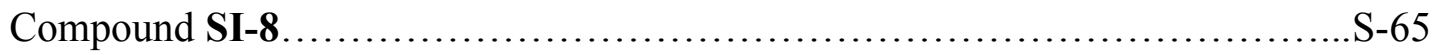

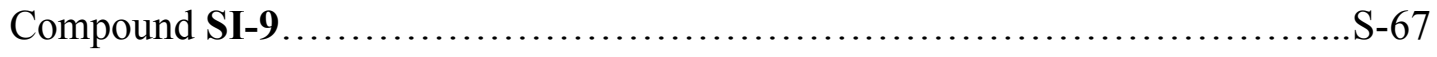

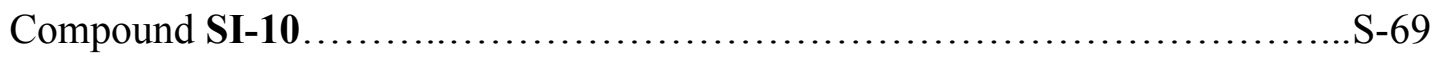

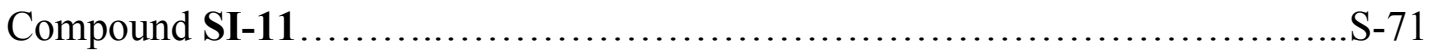

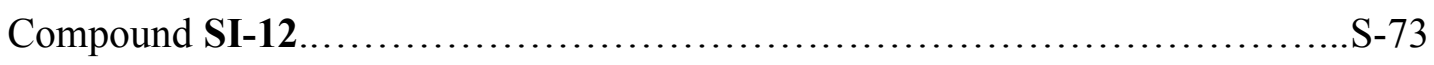

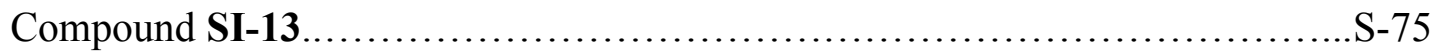

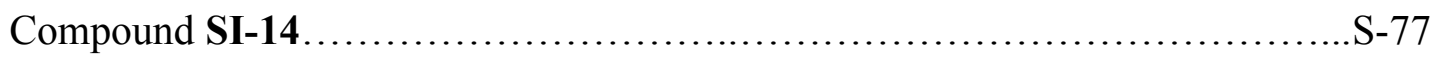




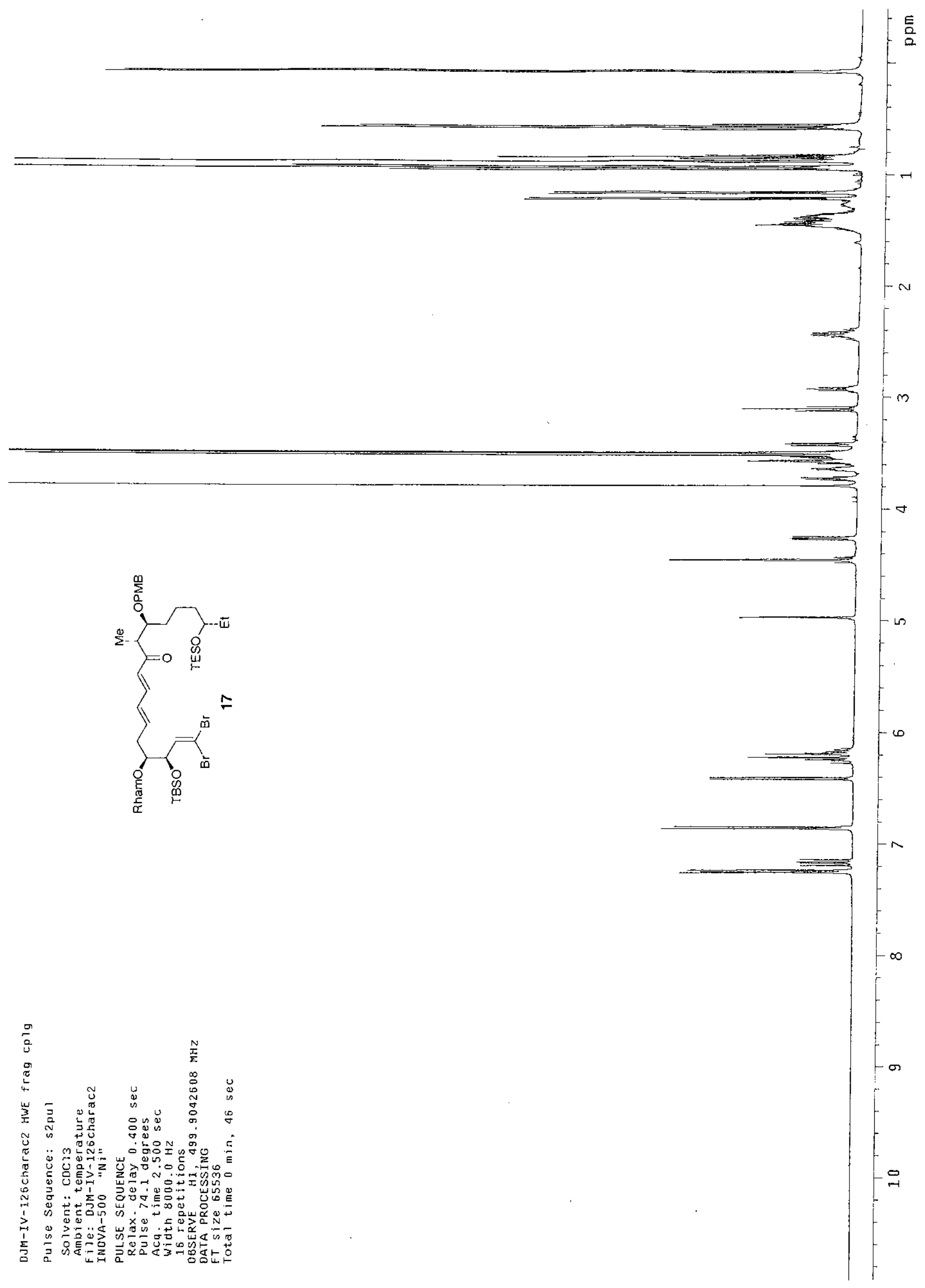




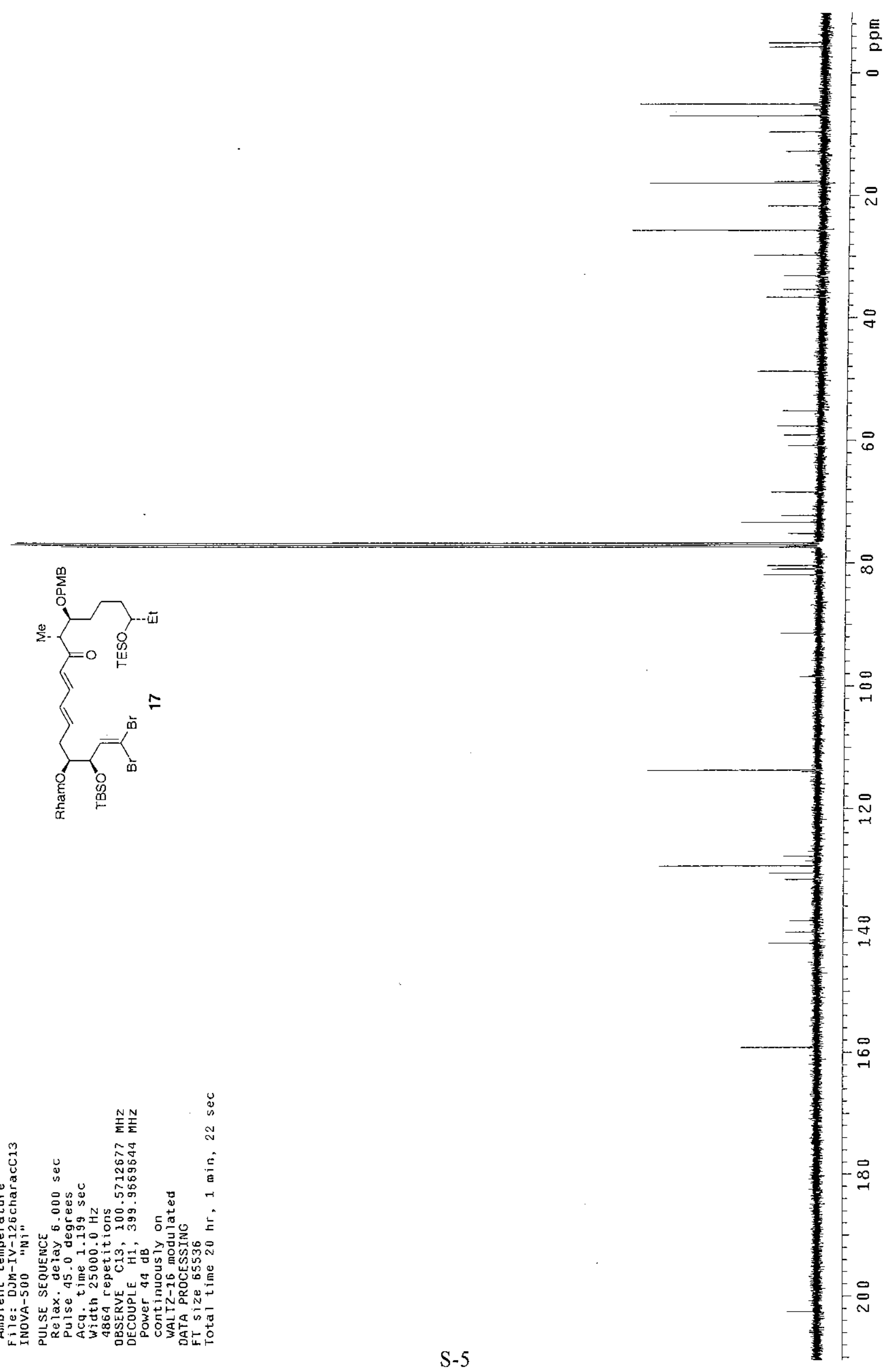




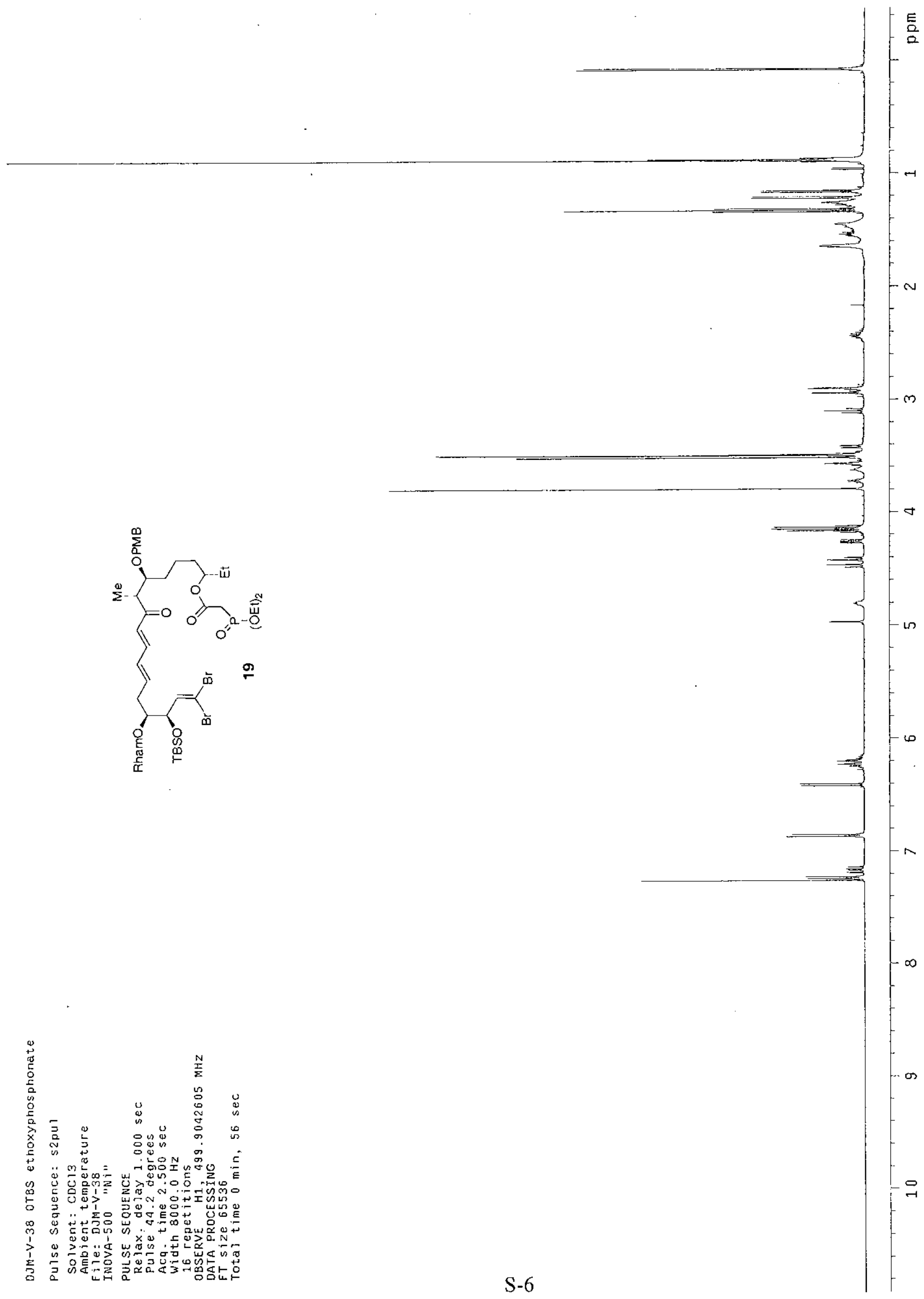




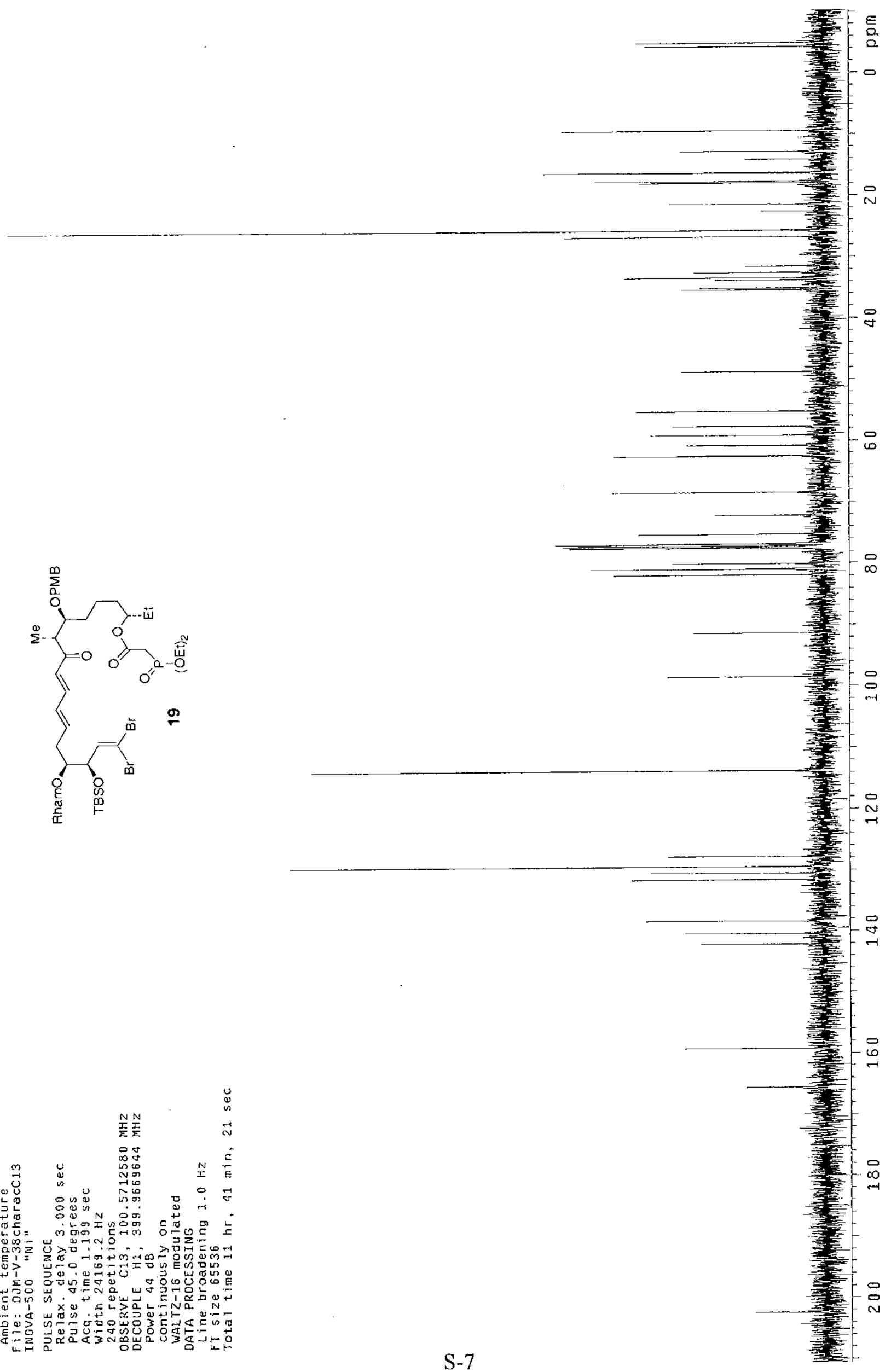




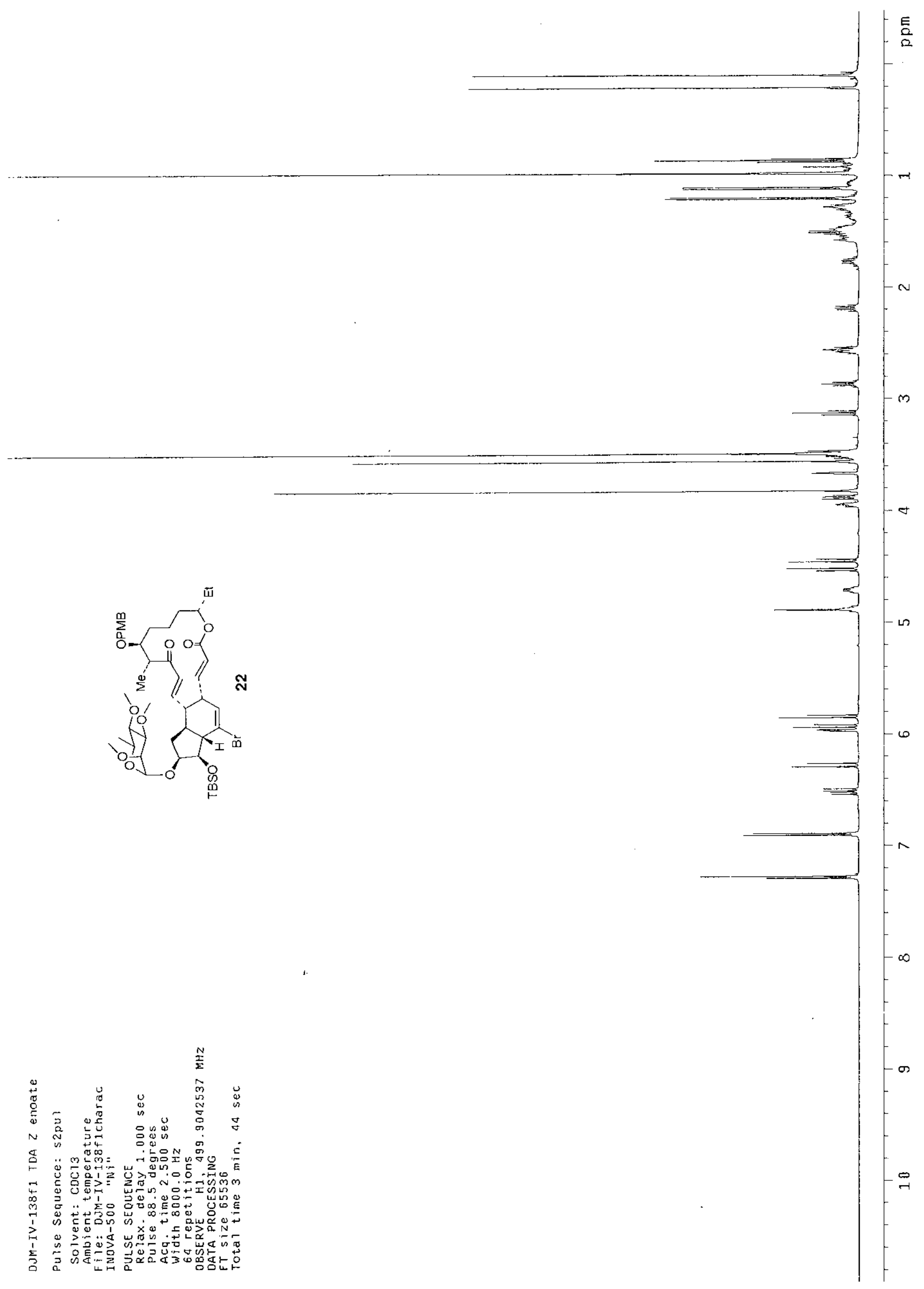




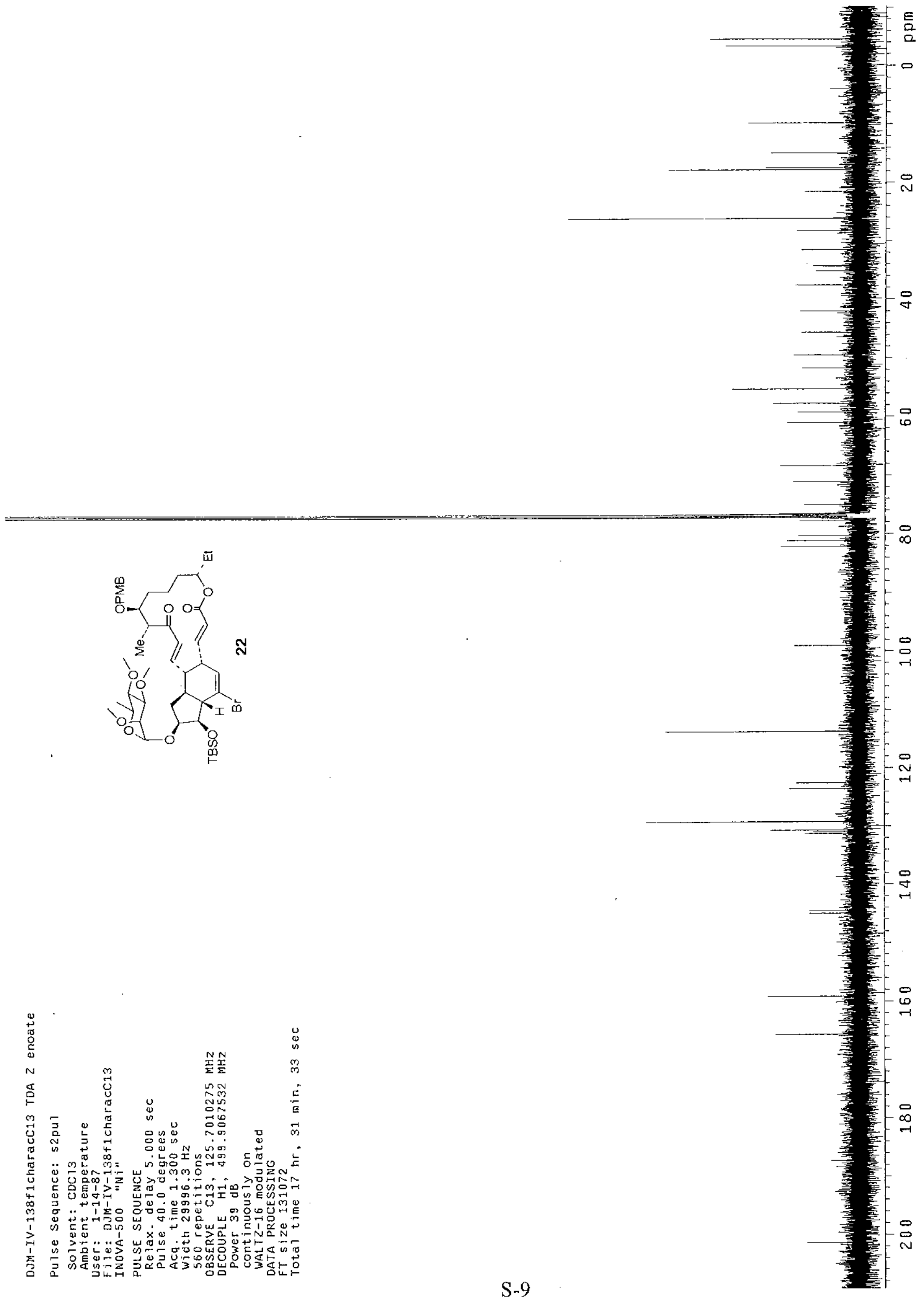




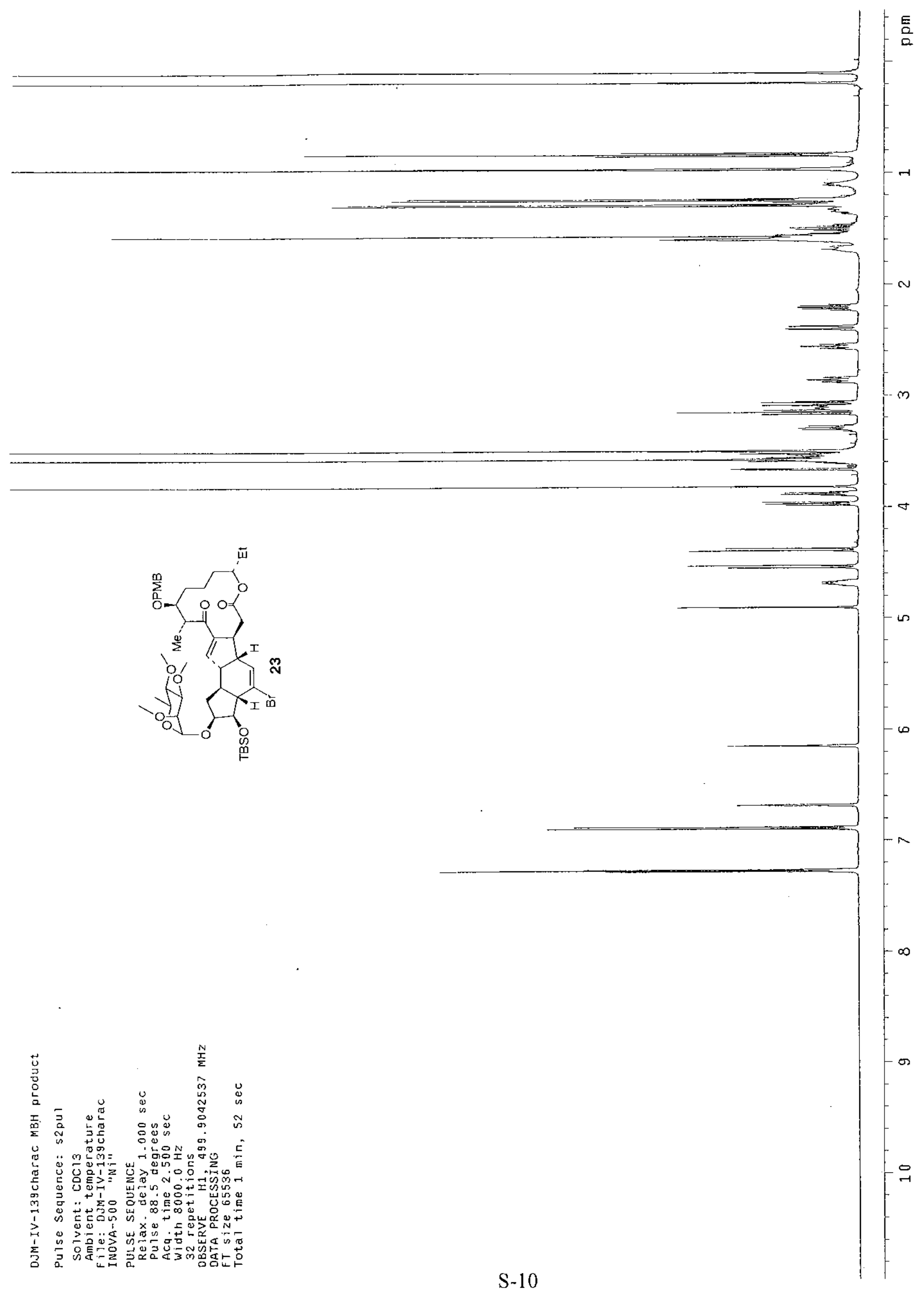




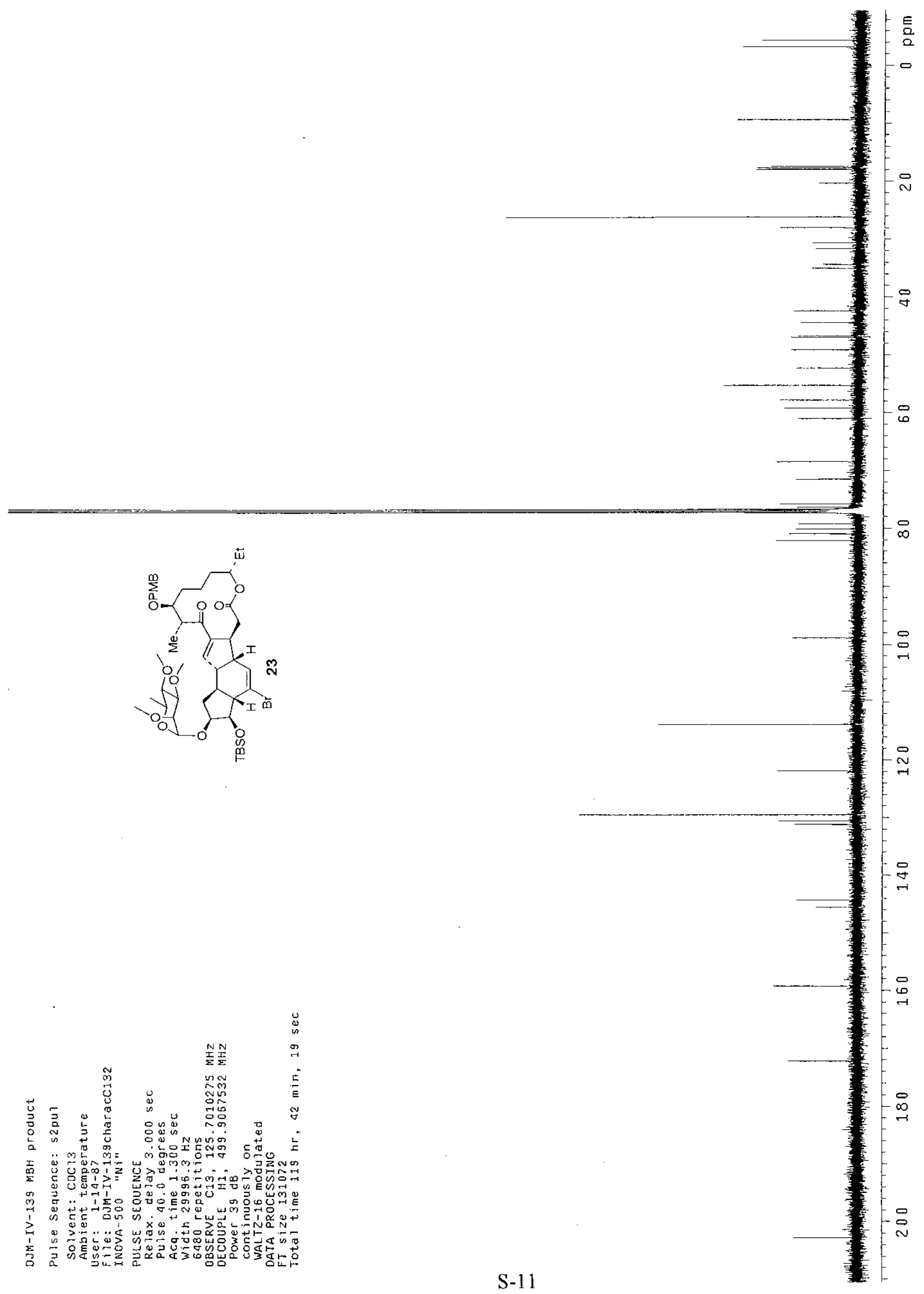




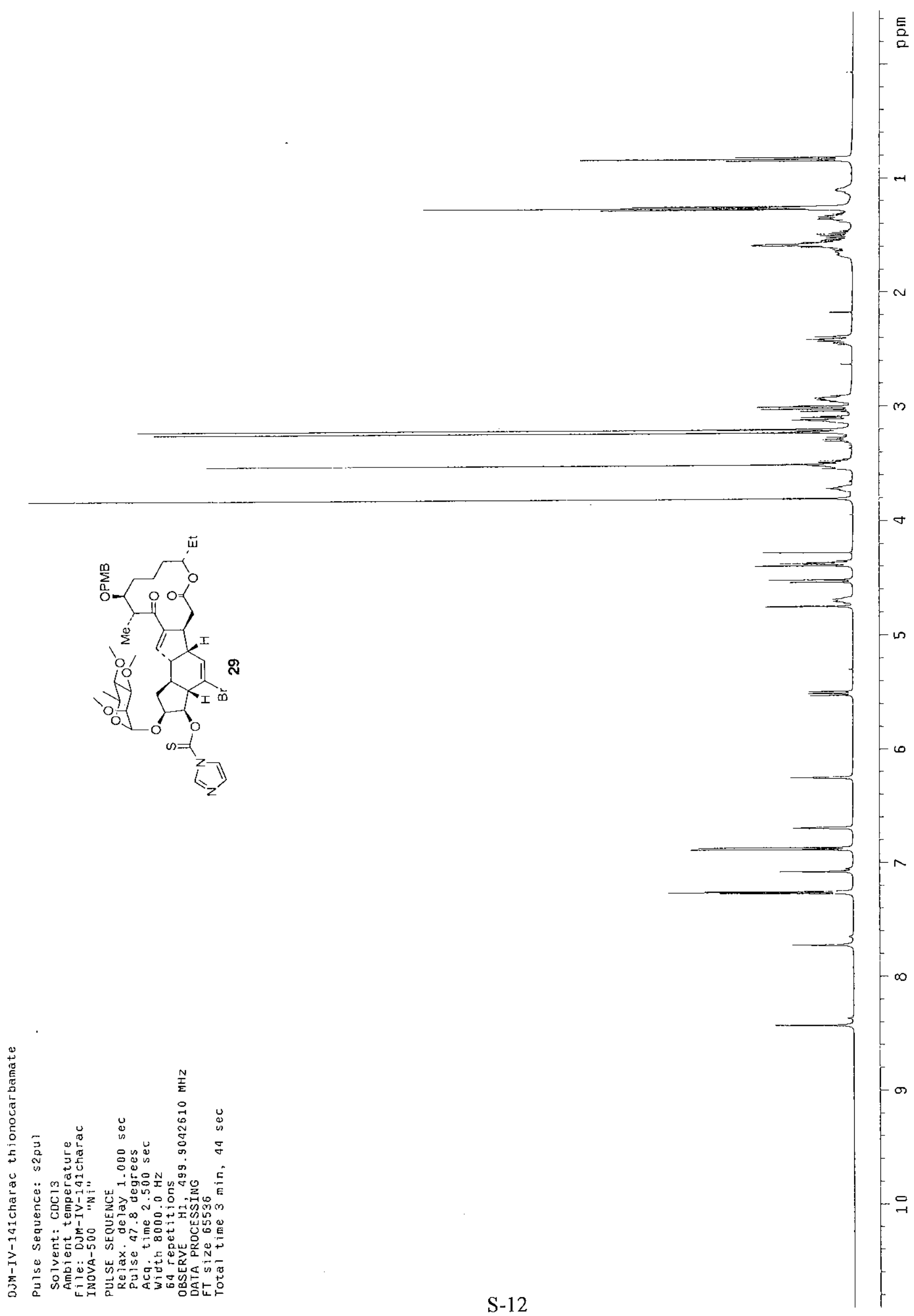




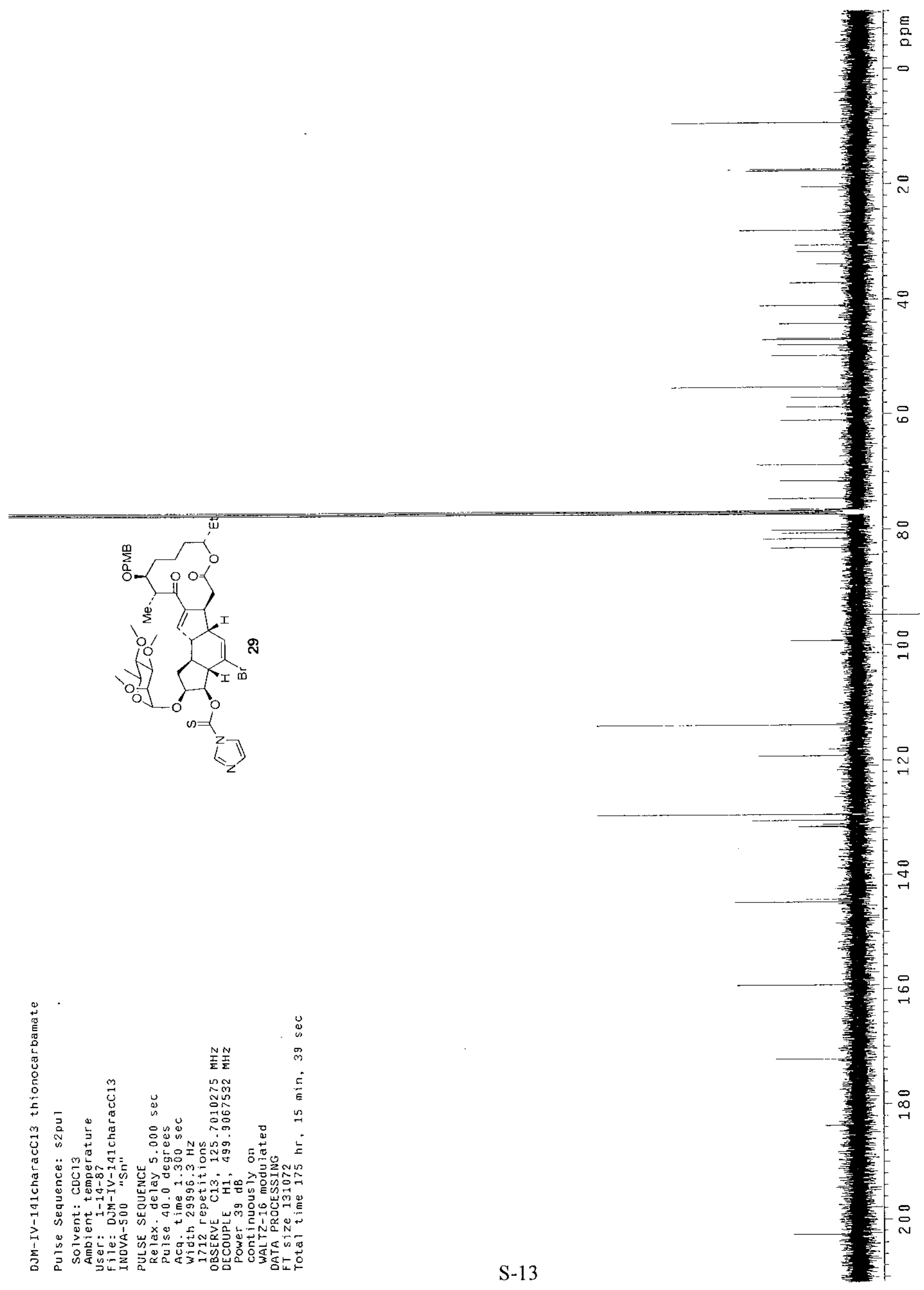




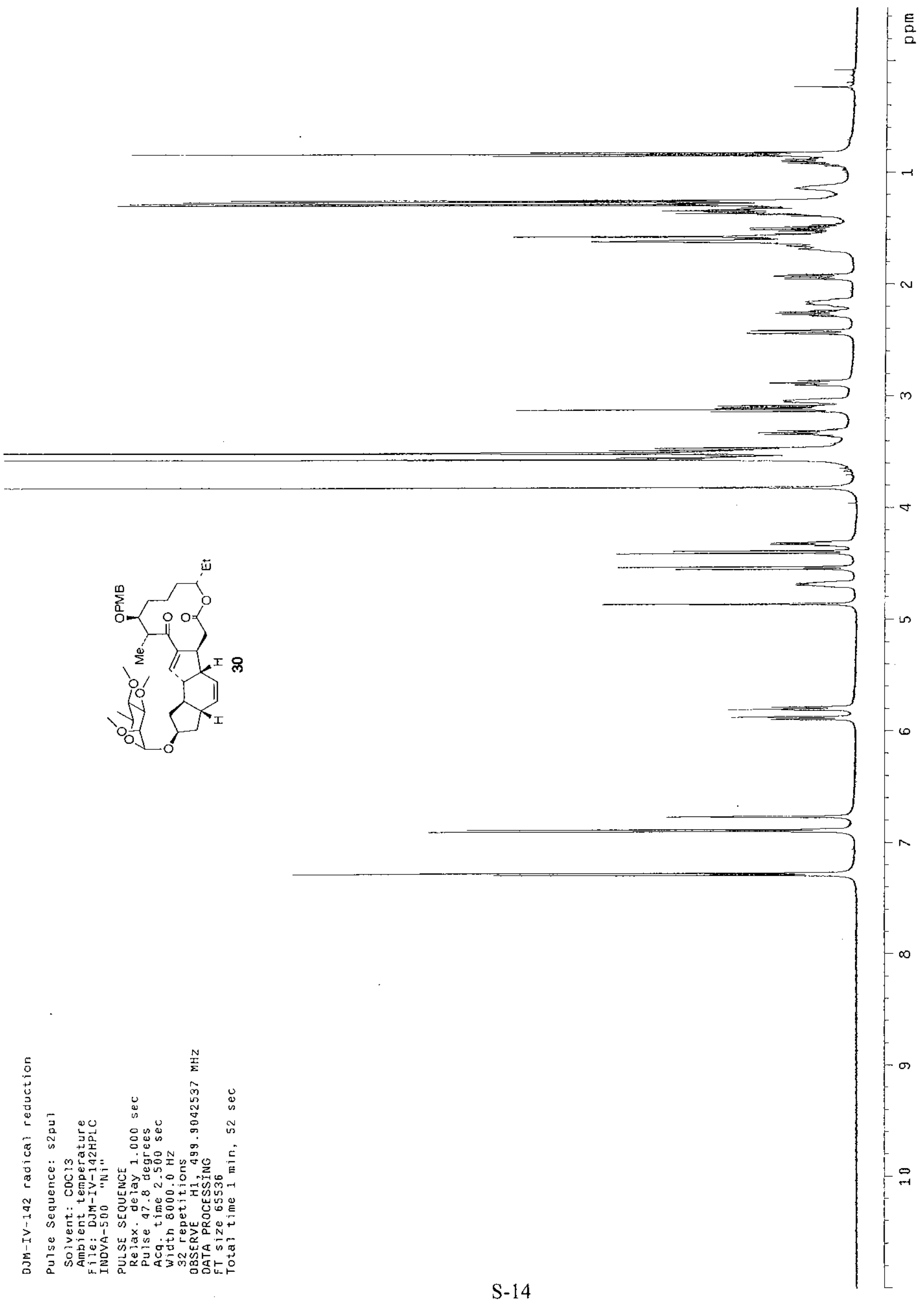




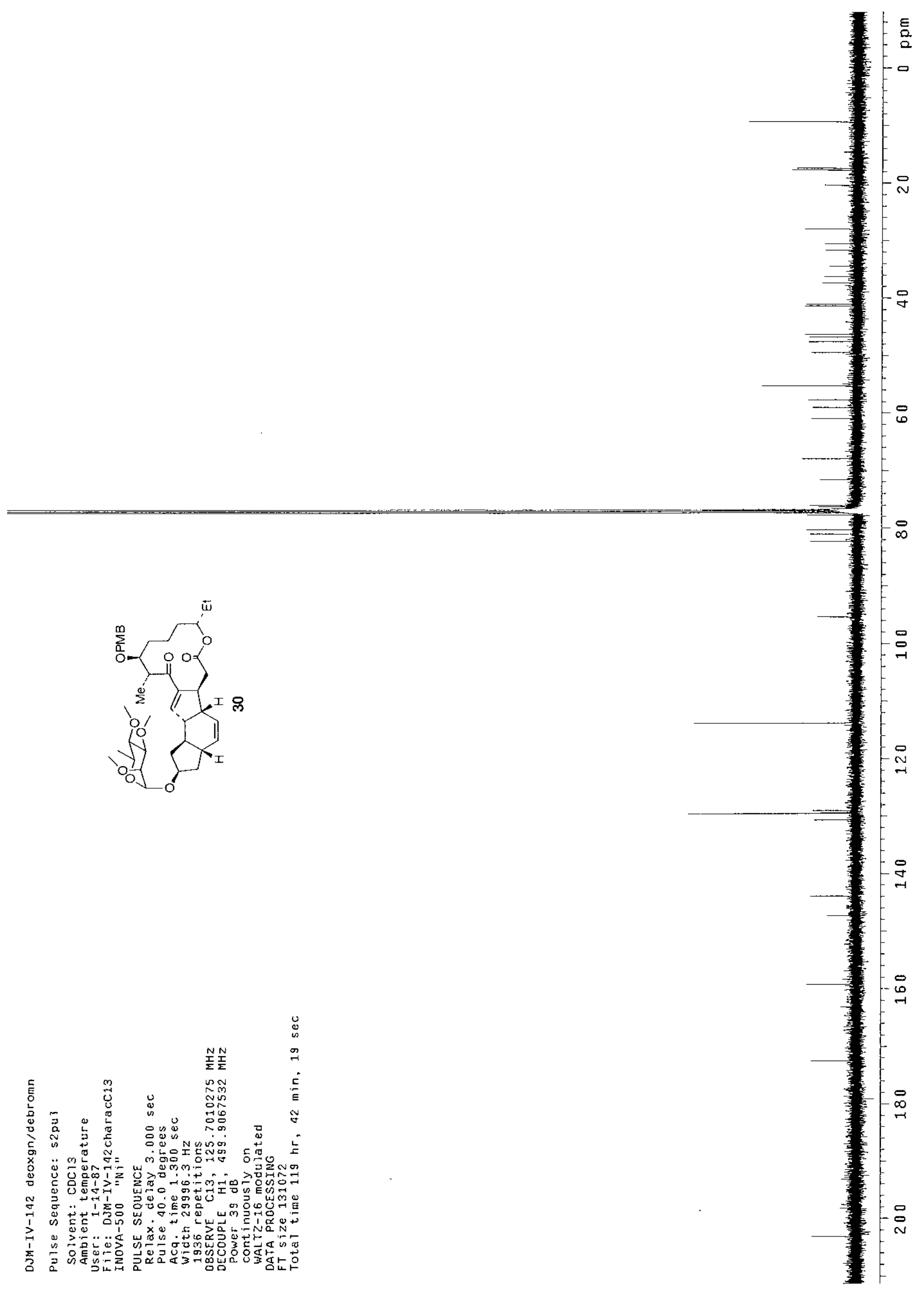




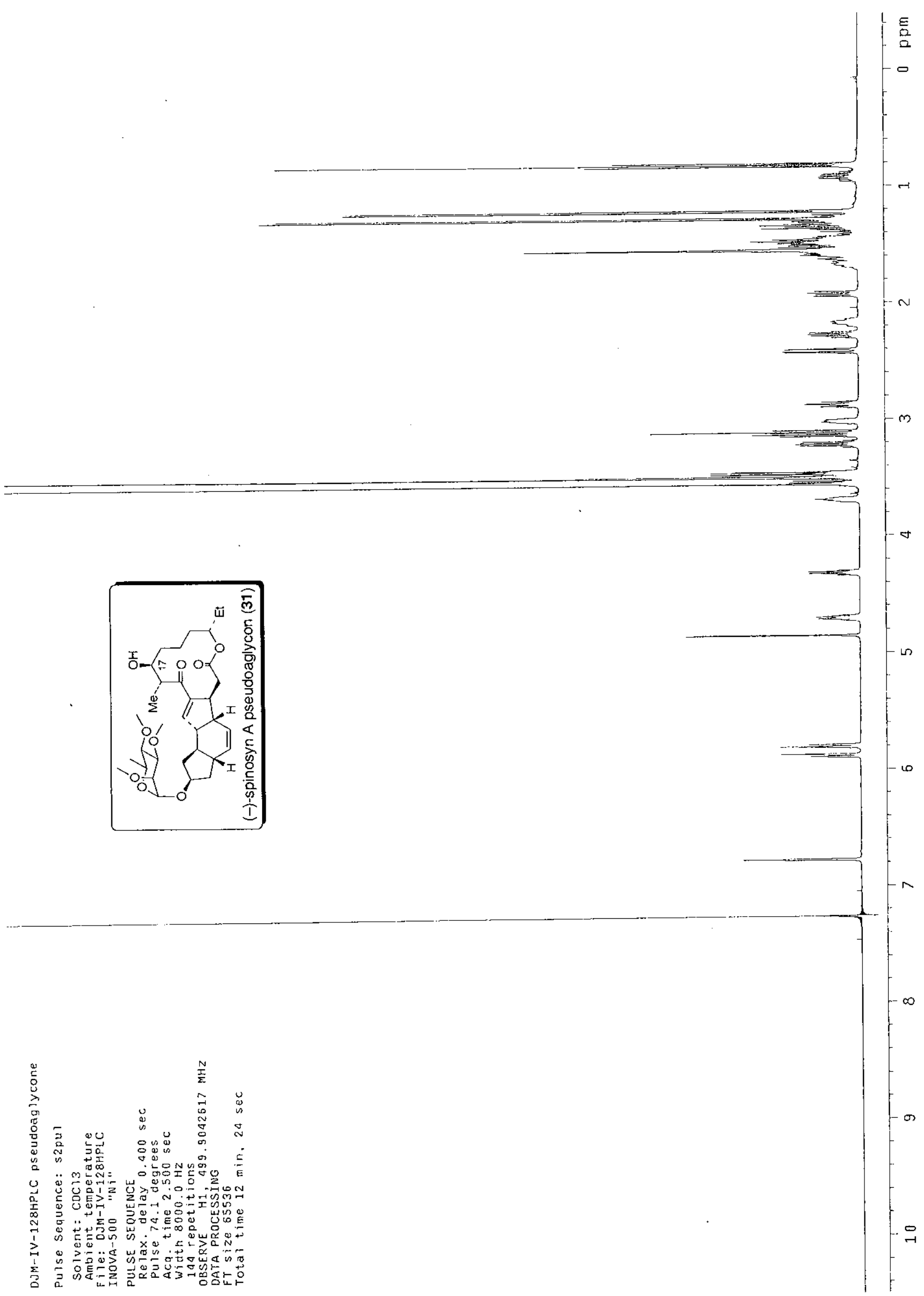

S-16 


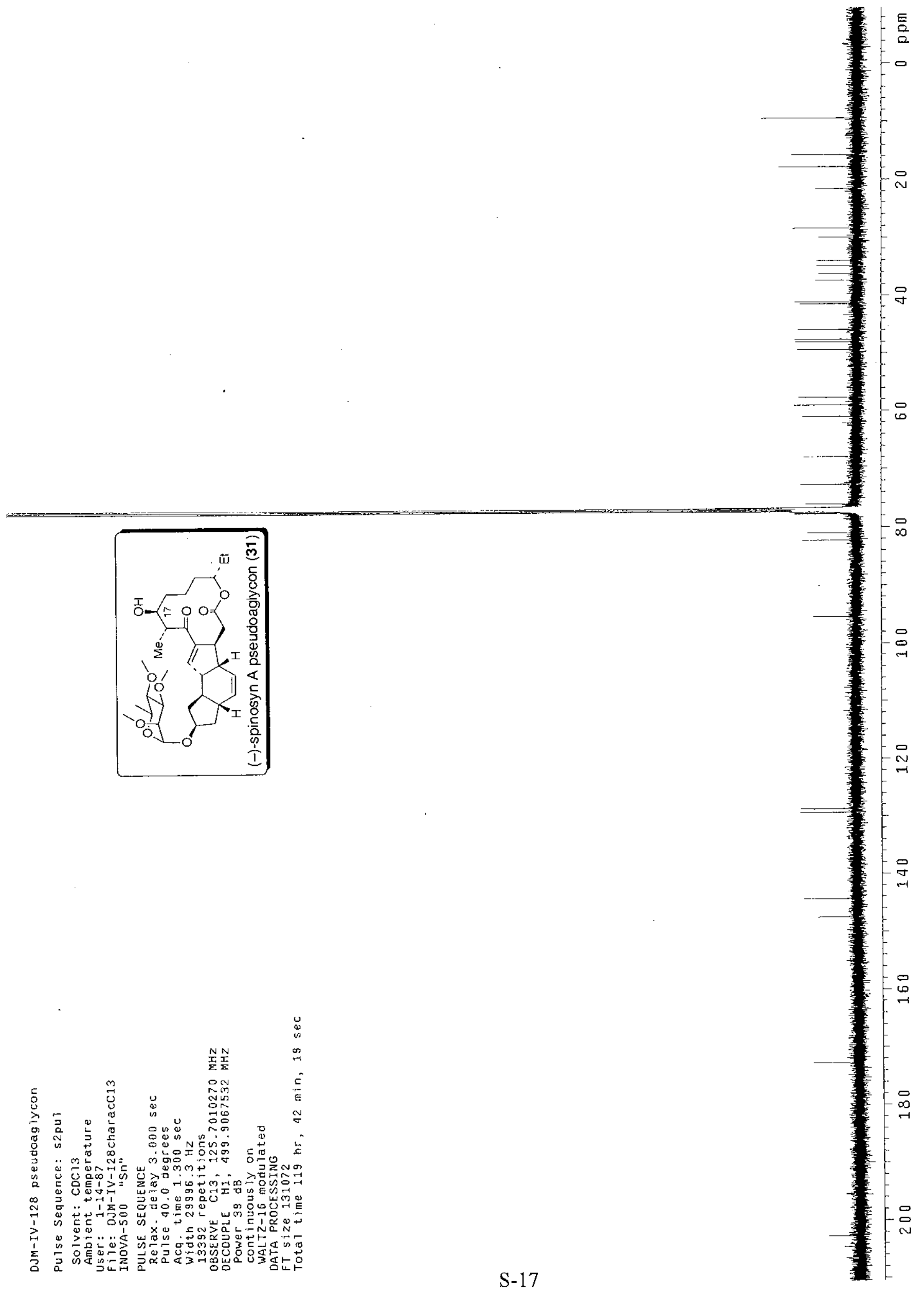




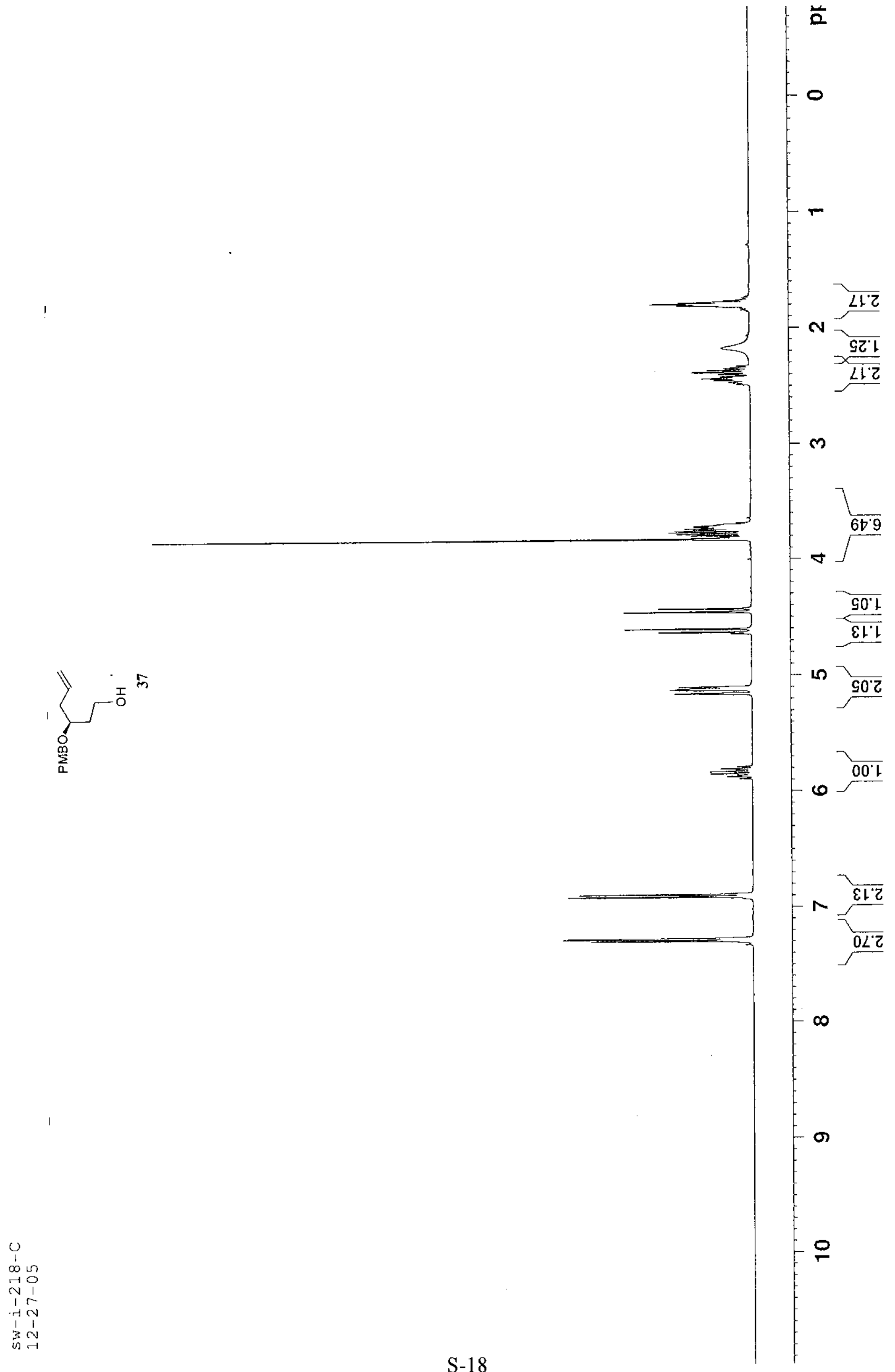




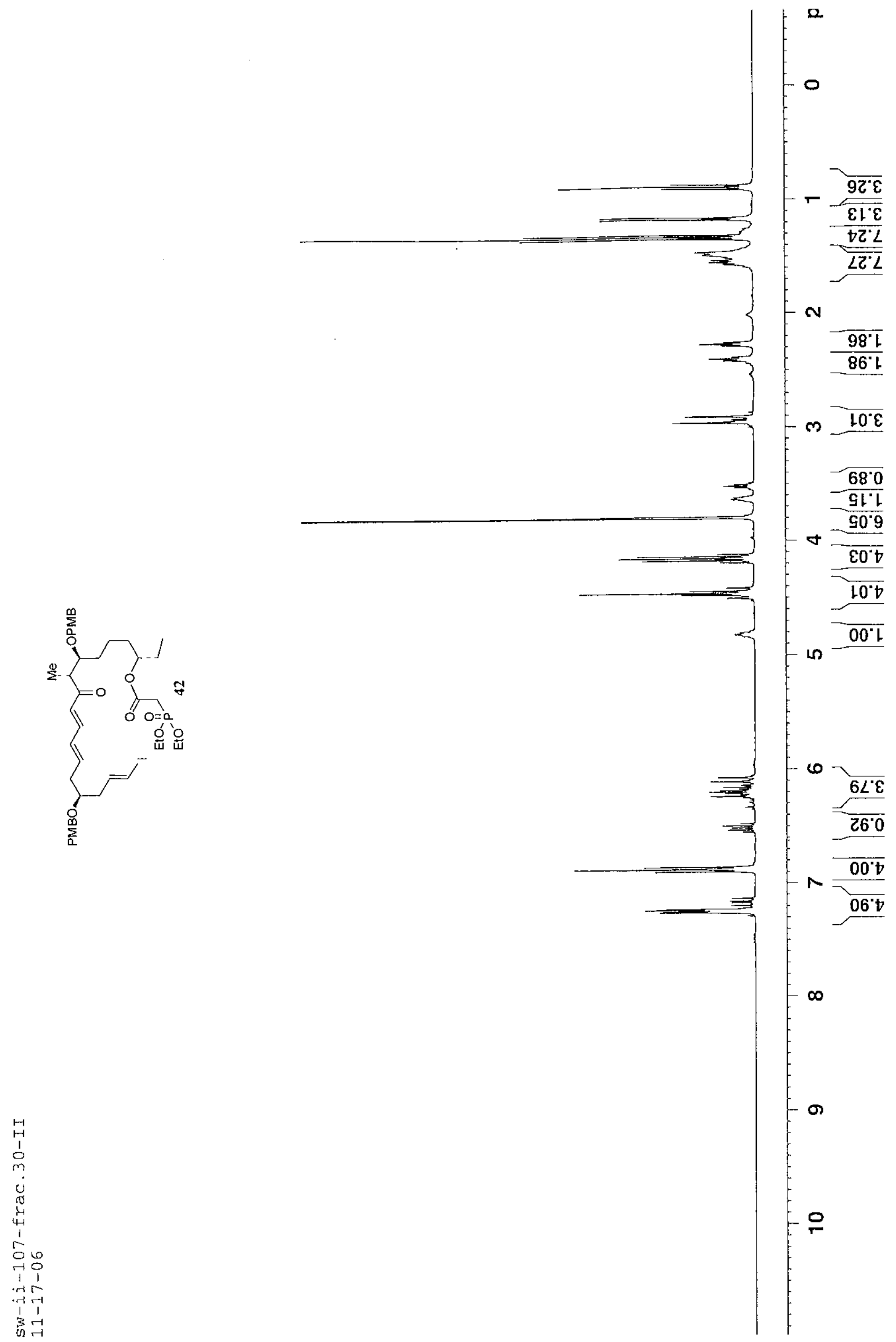




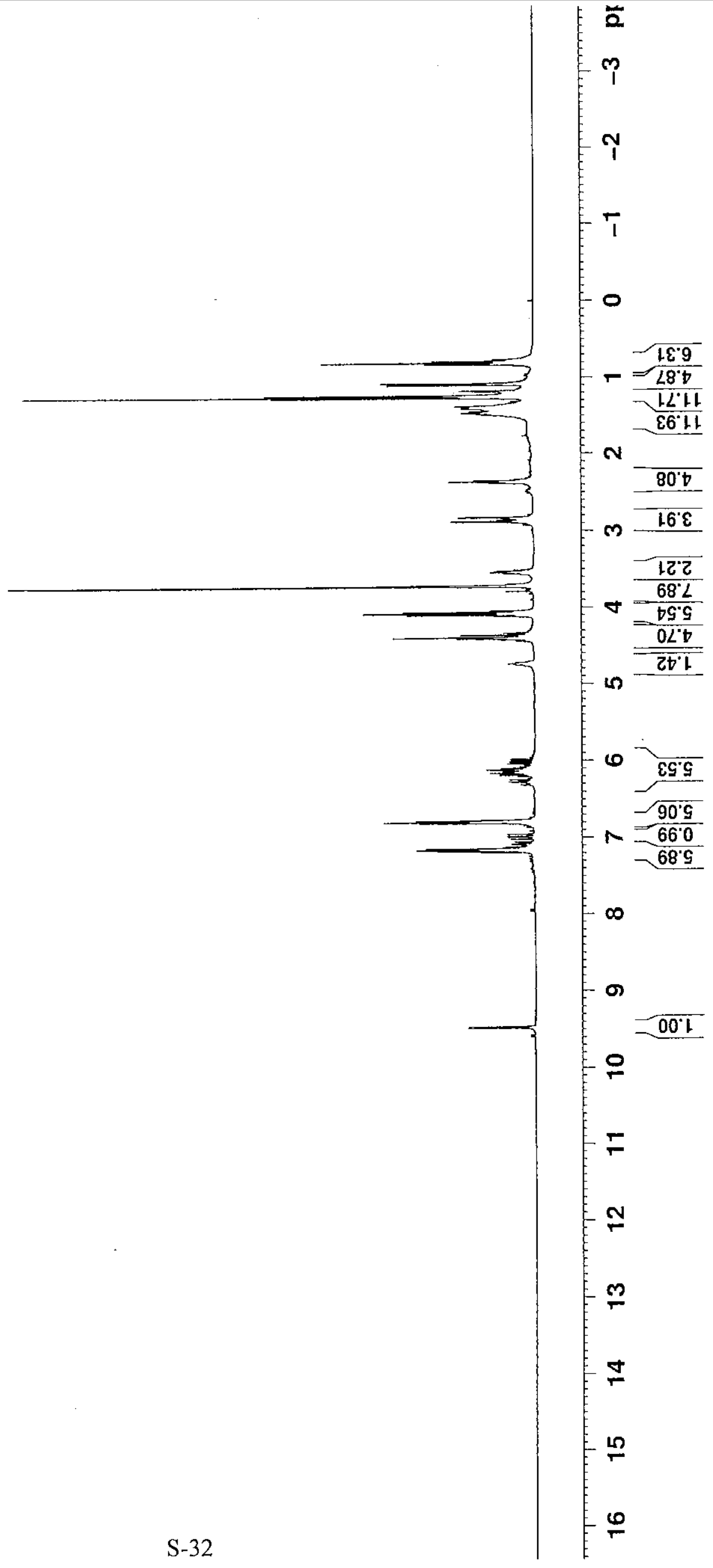


$68^{\circ} 6$

$69 \cdot \mathrm{C}$. ...................

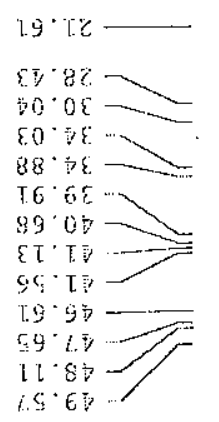

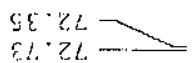

(1) 1.91

$20 \cdot 2, \longrightarrow=$

\&.8. $1.1-$

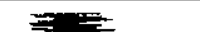




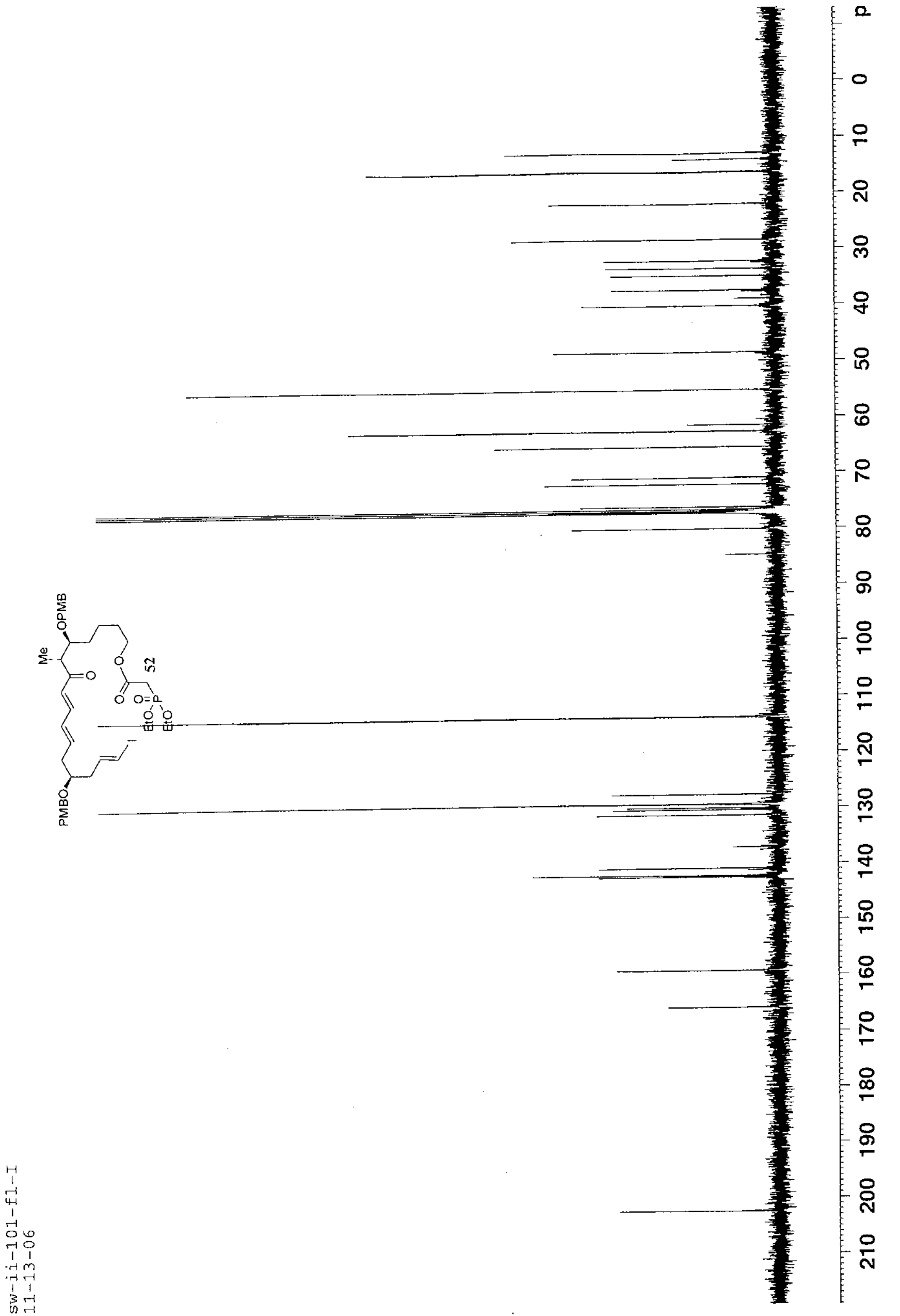




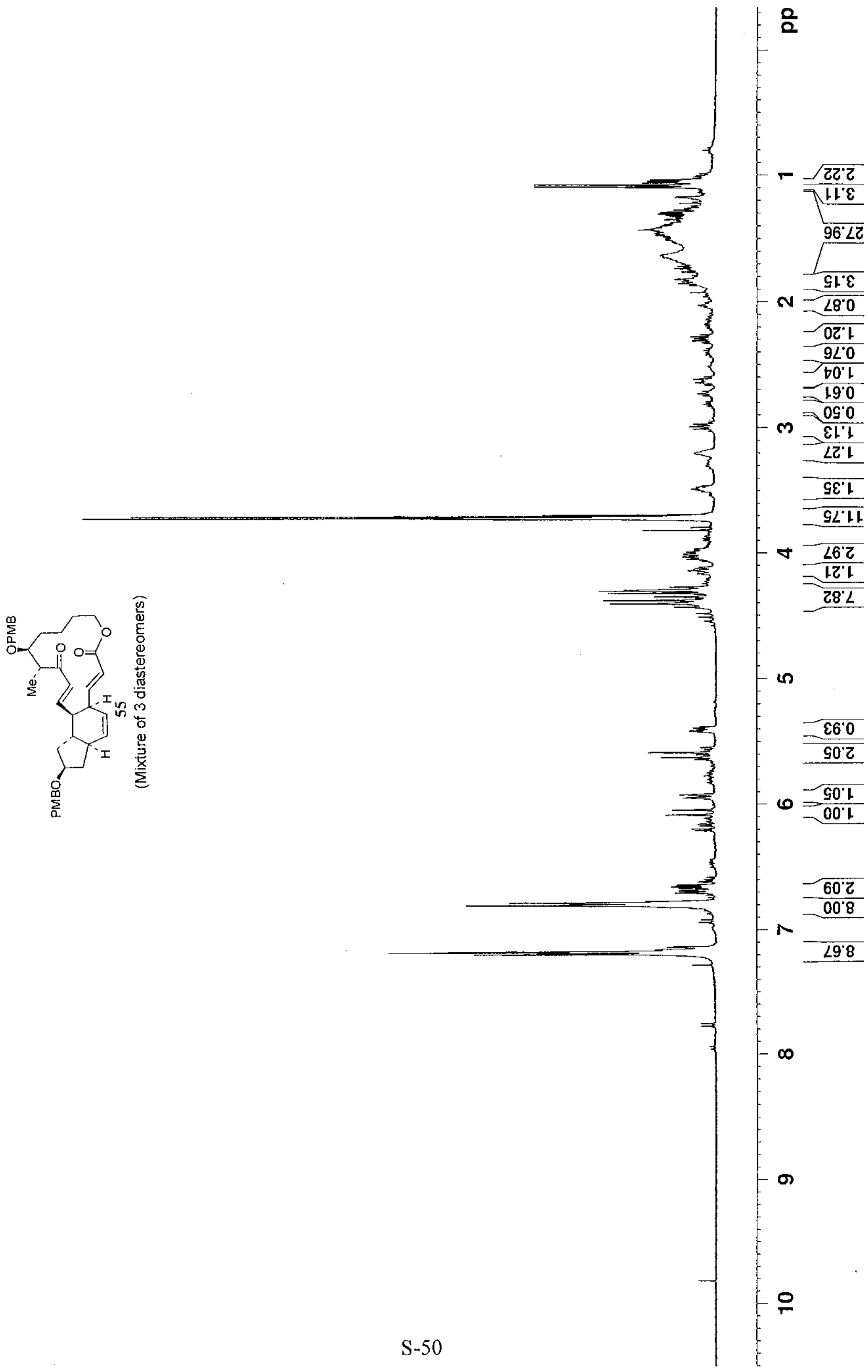




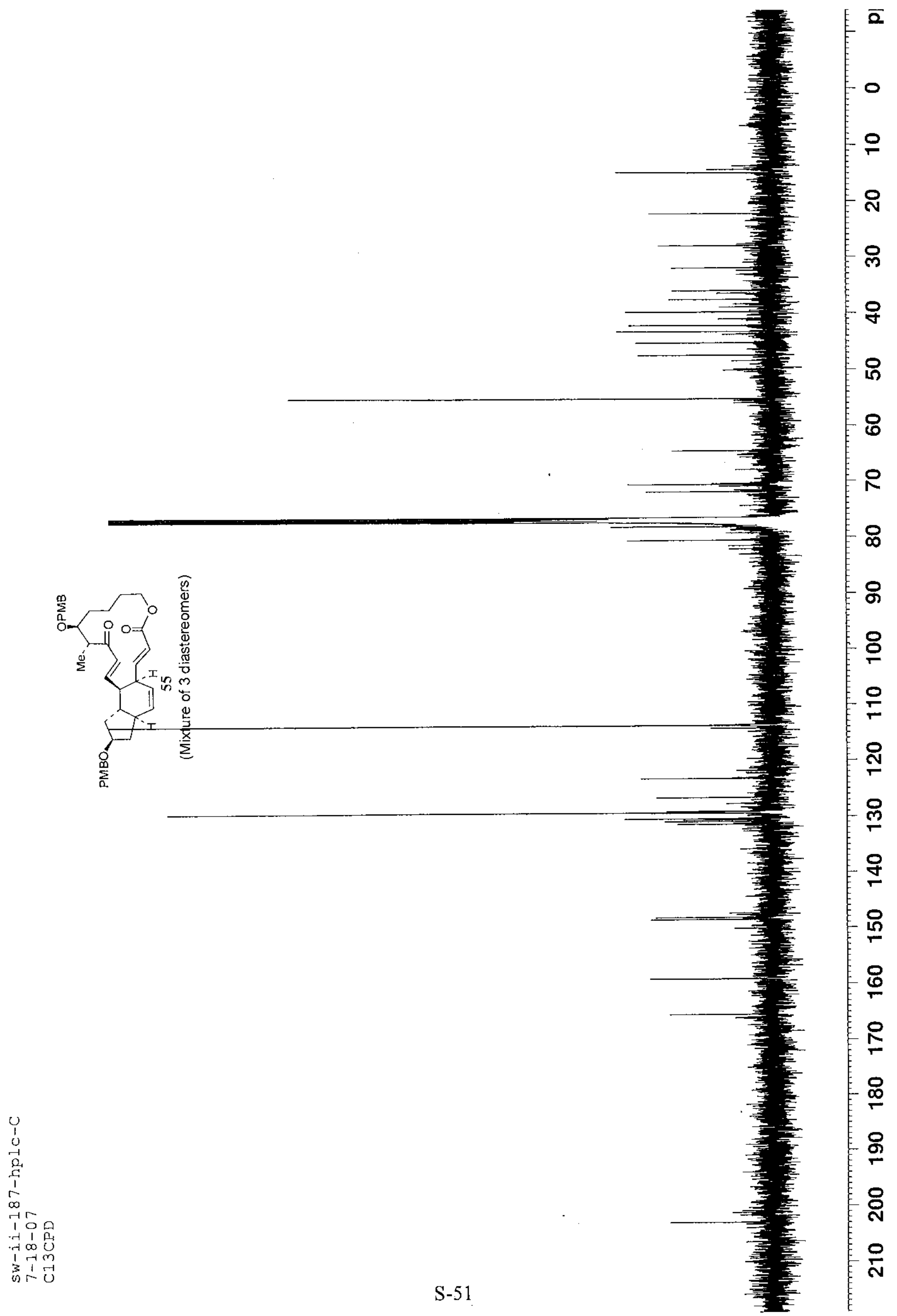




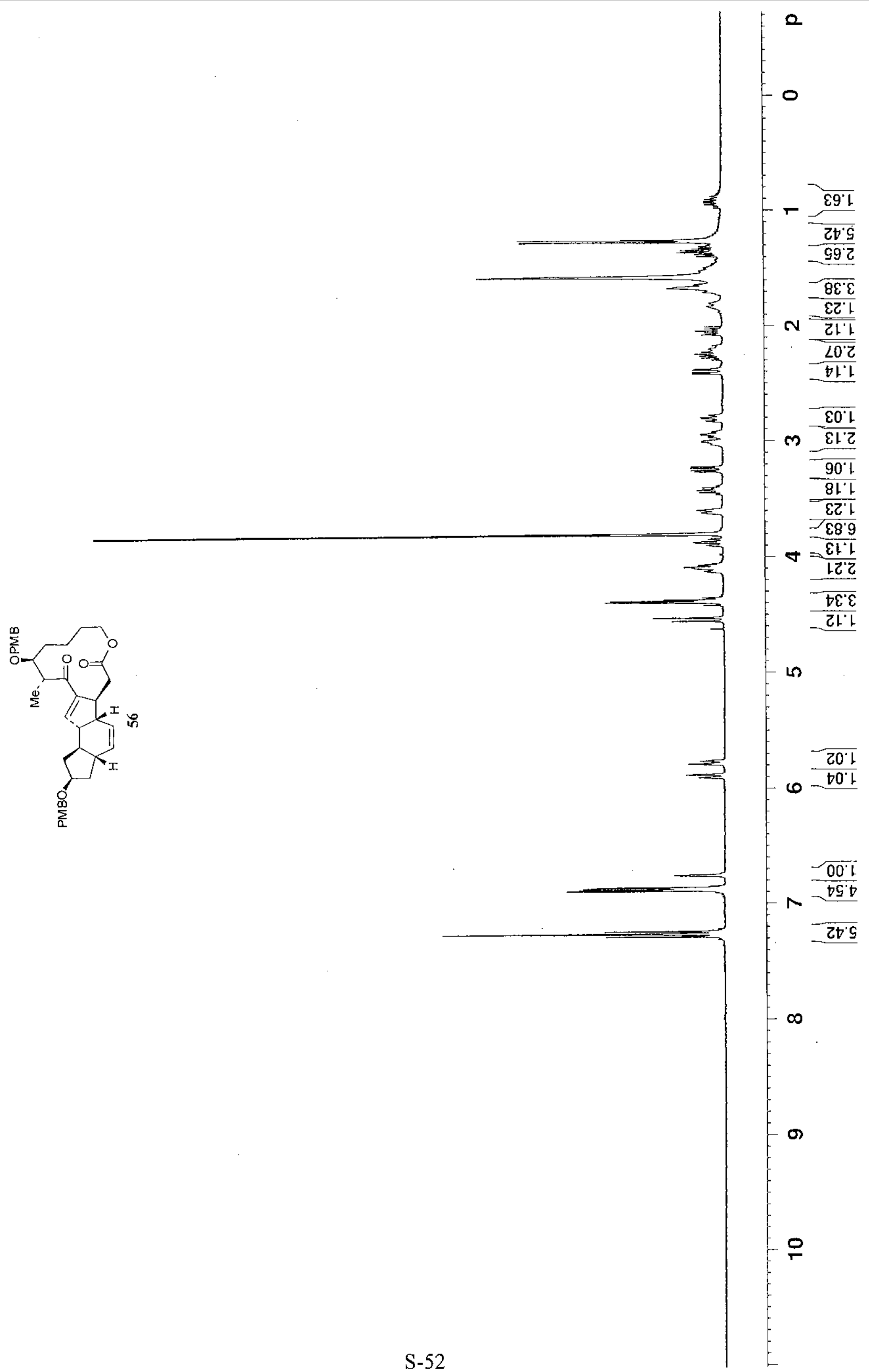




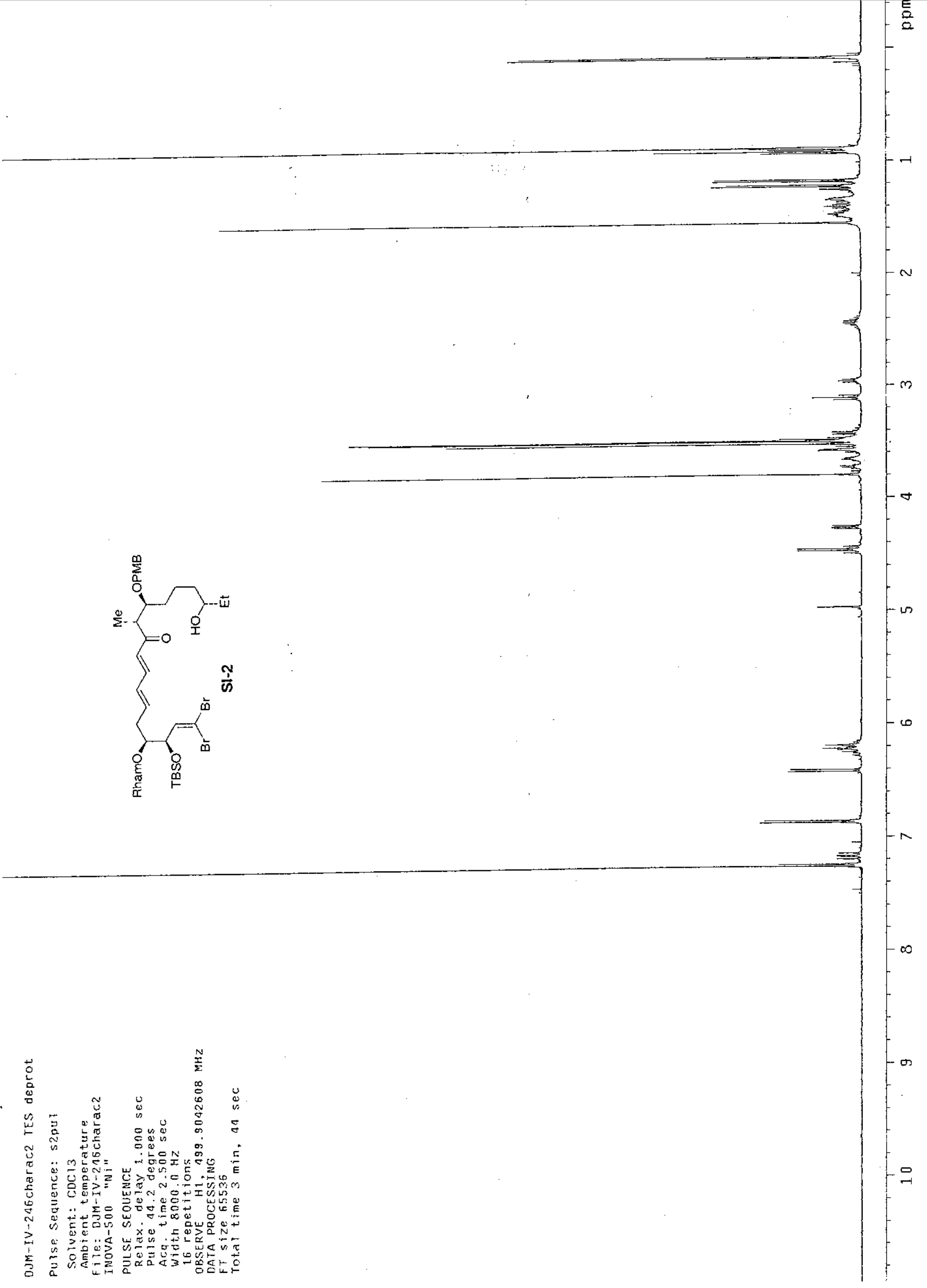




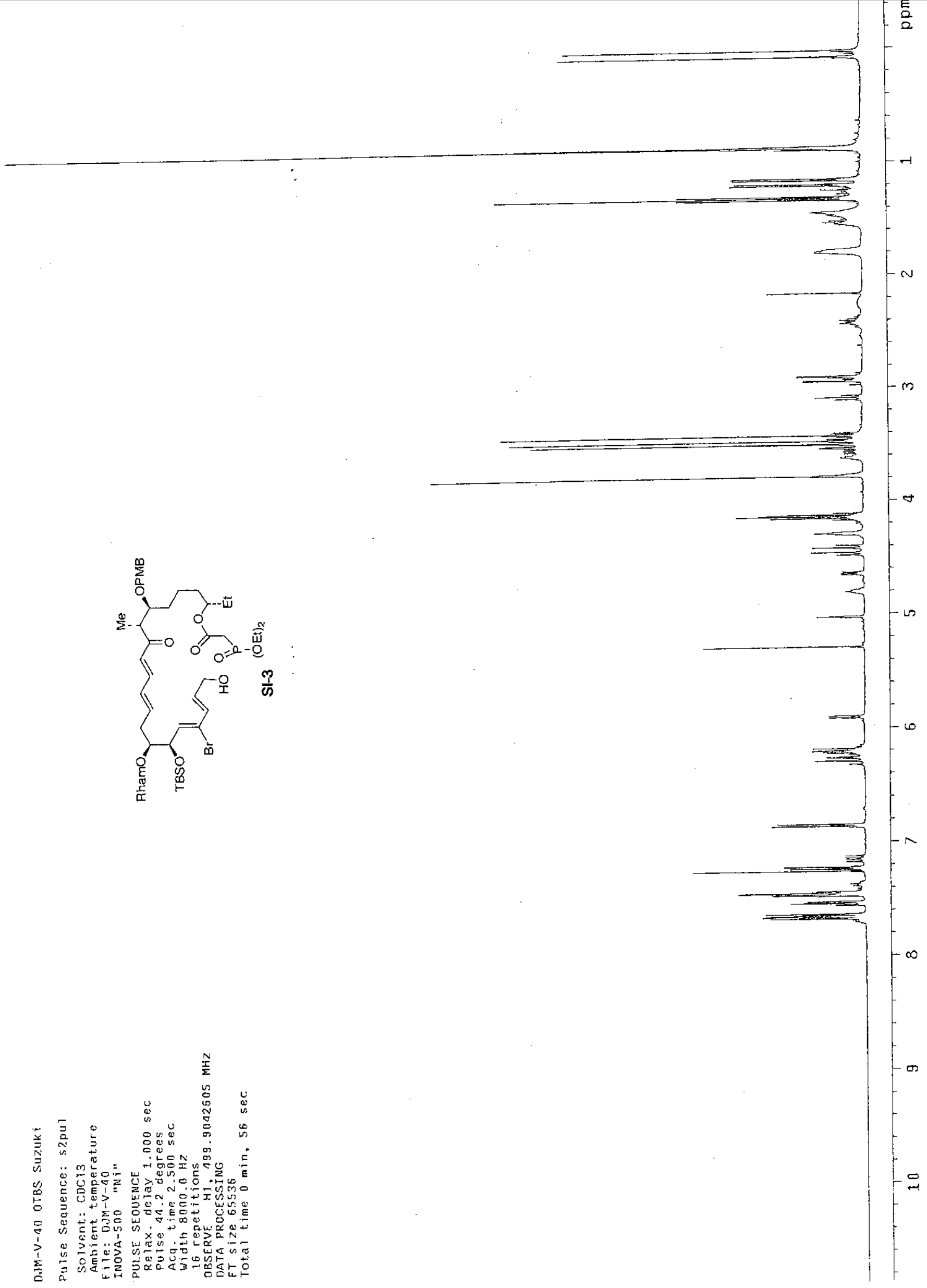




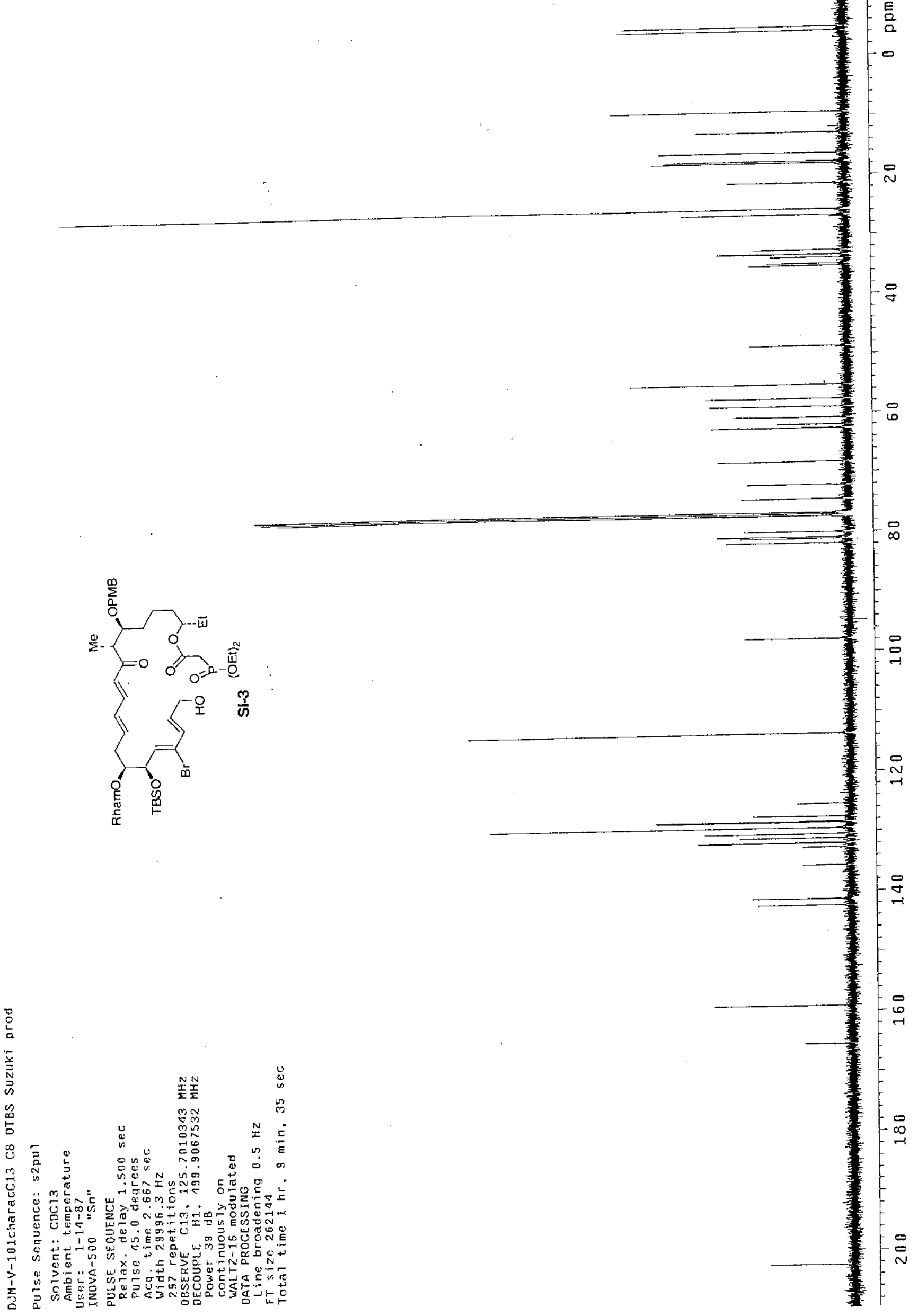



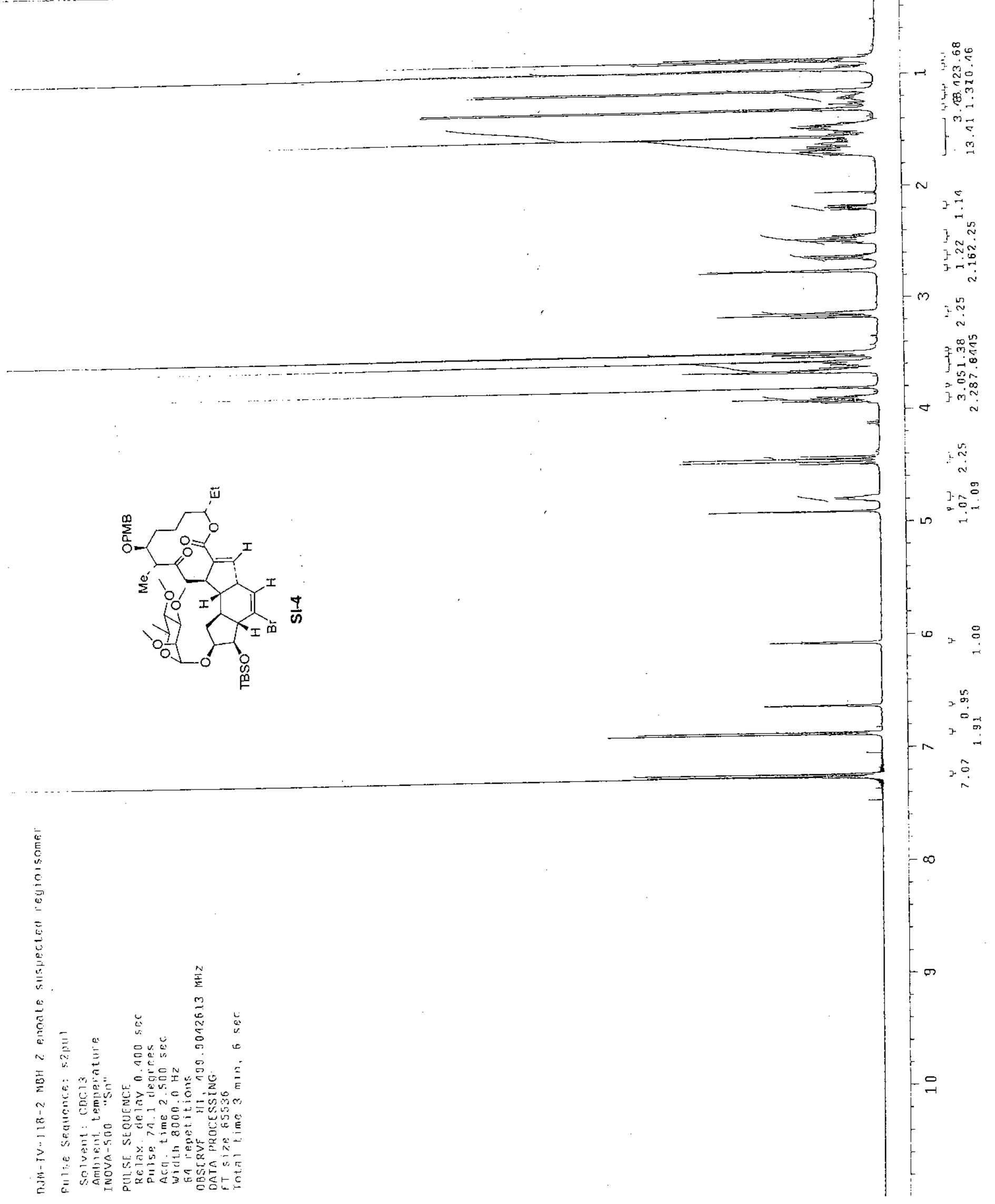

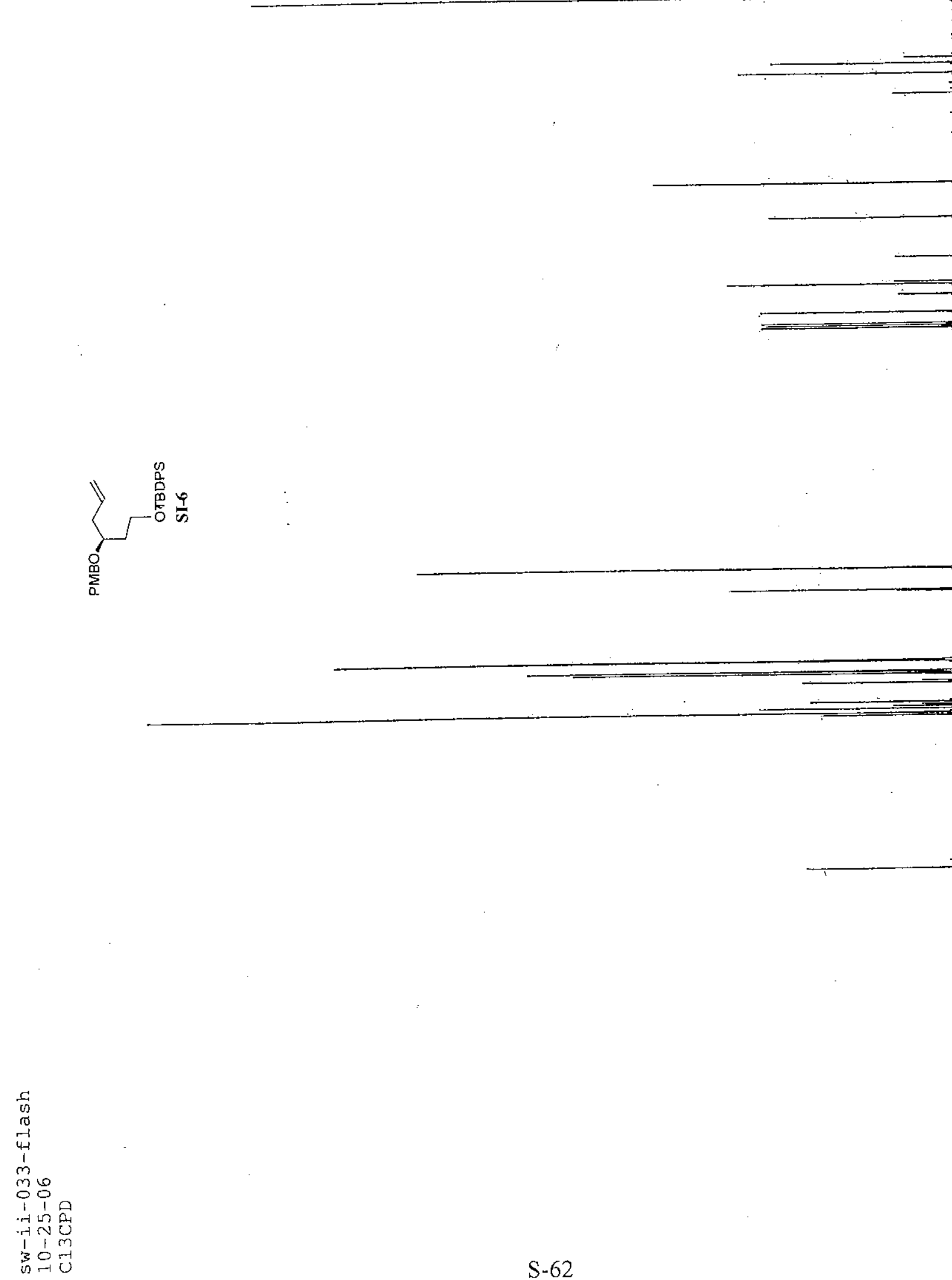


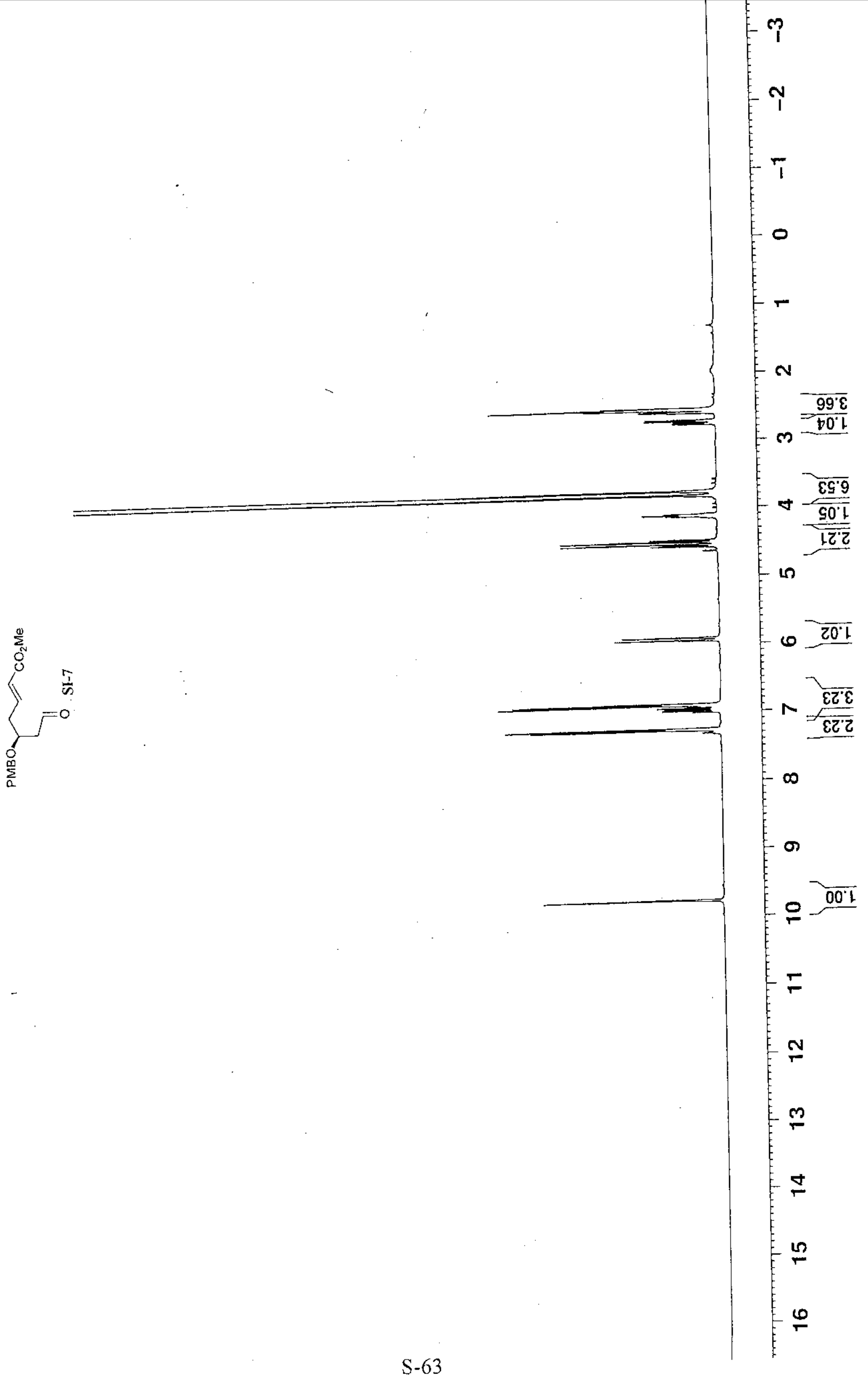



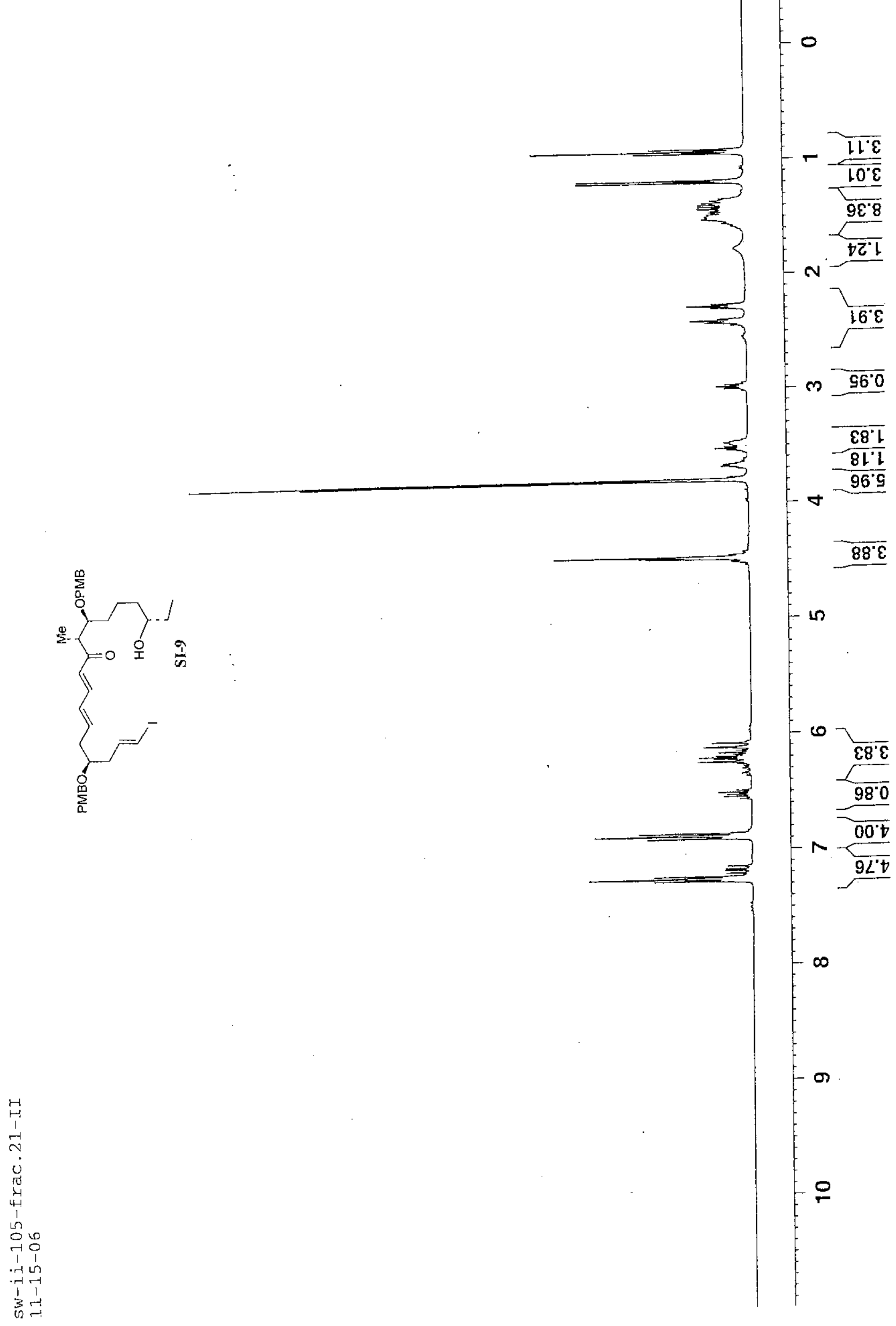


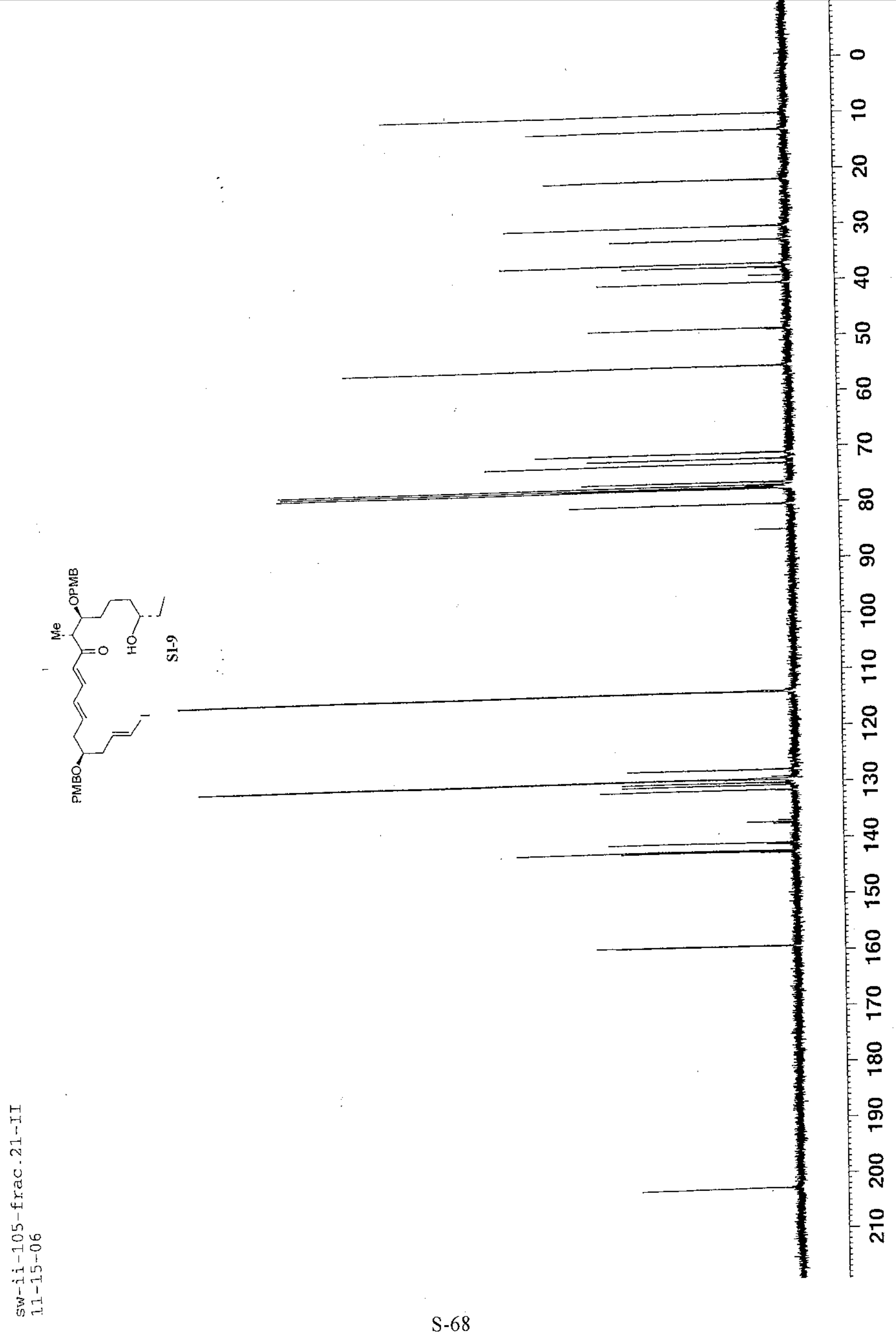



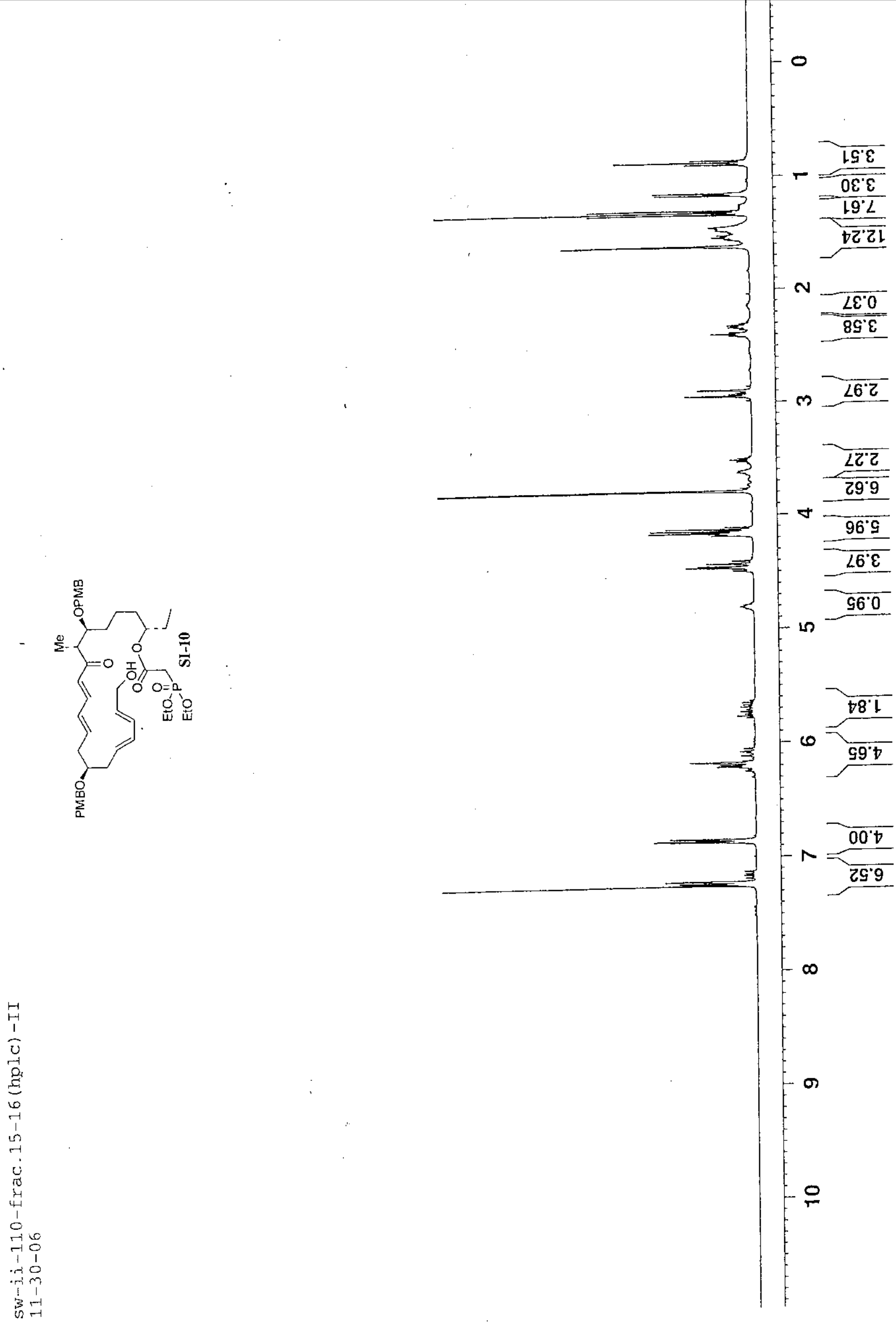


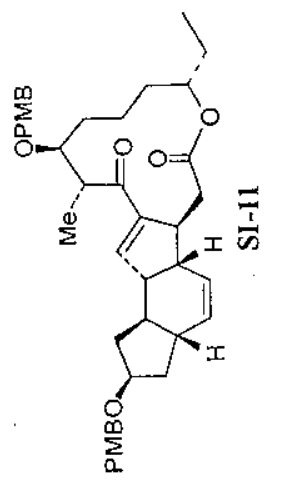




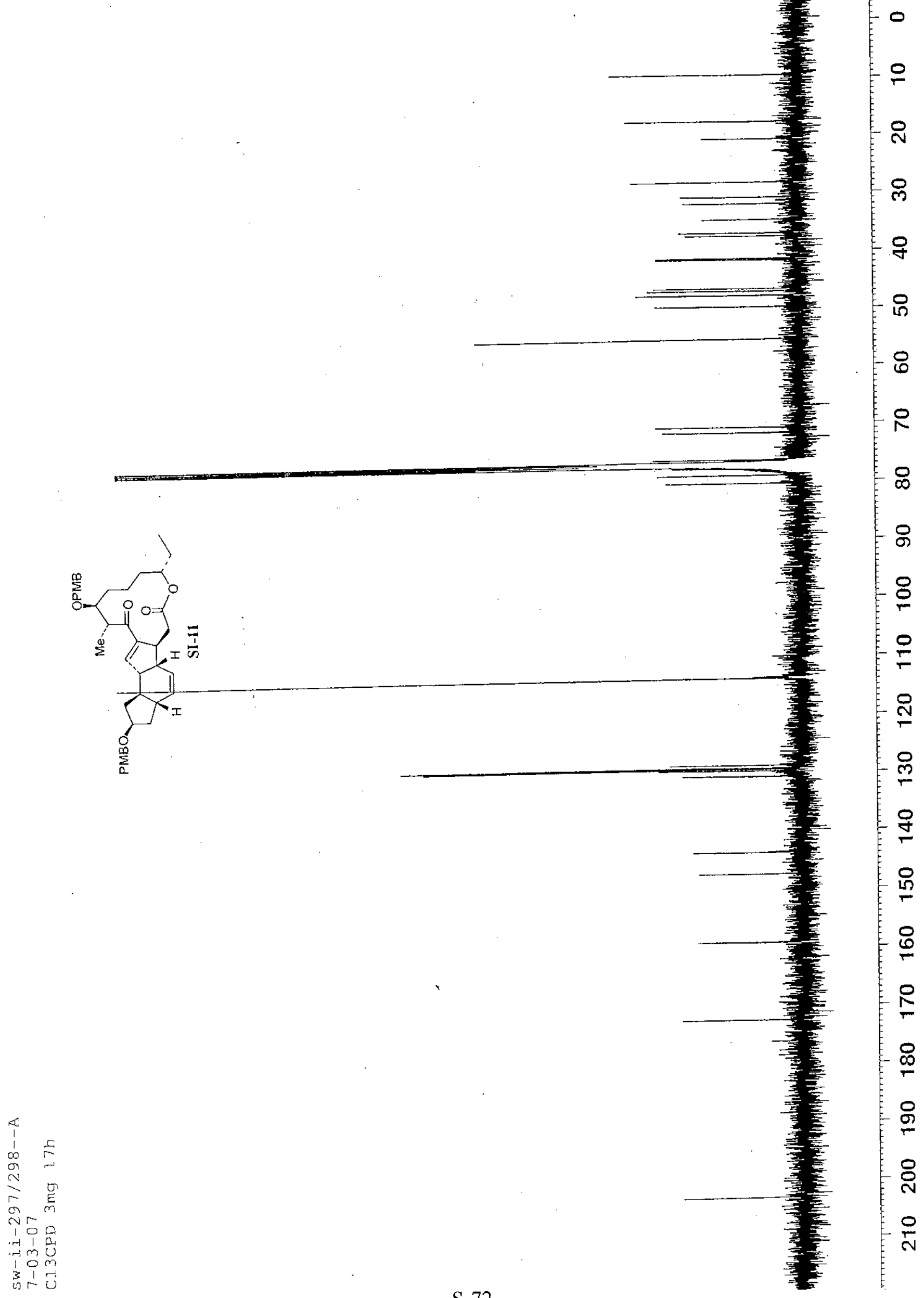




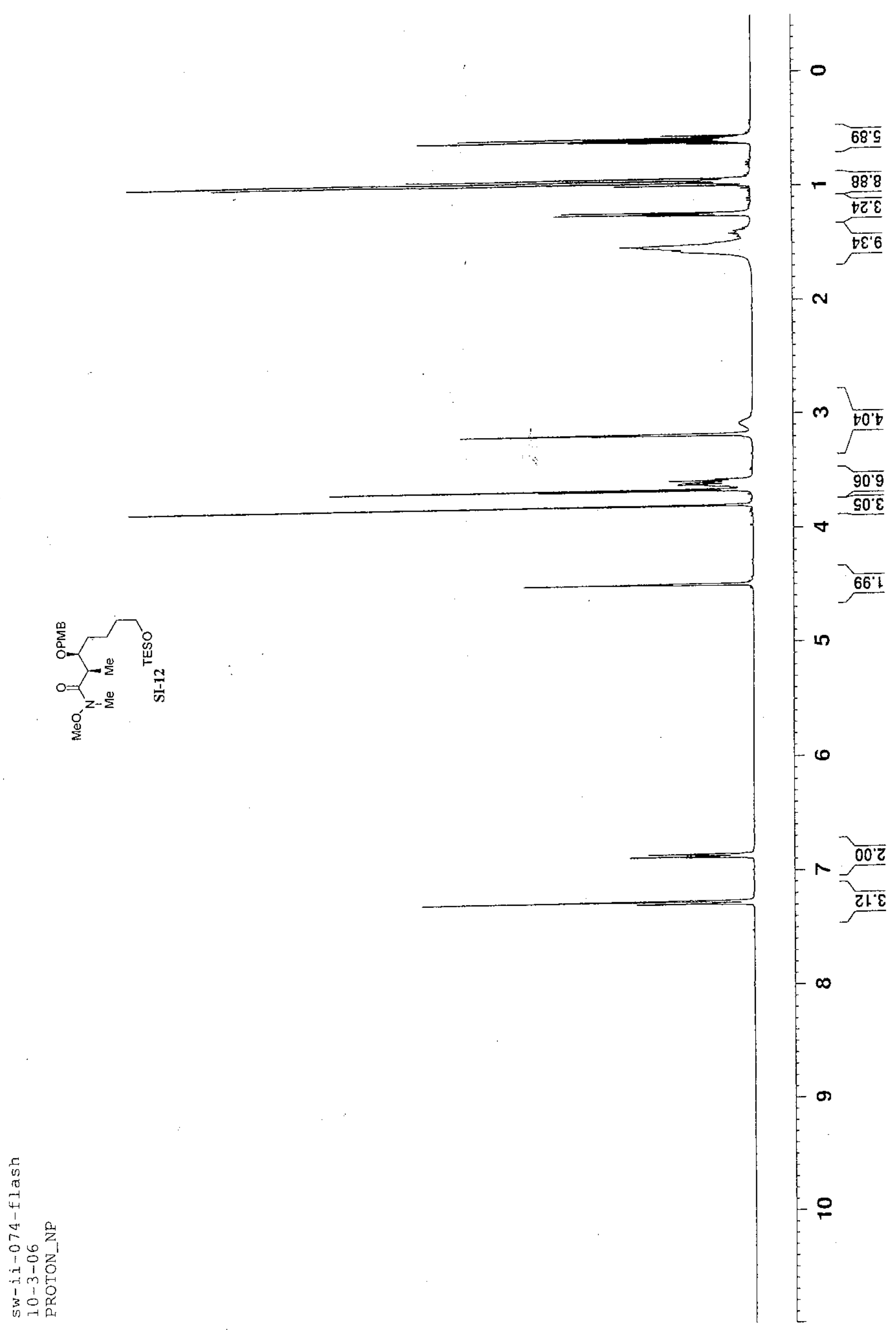




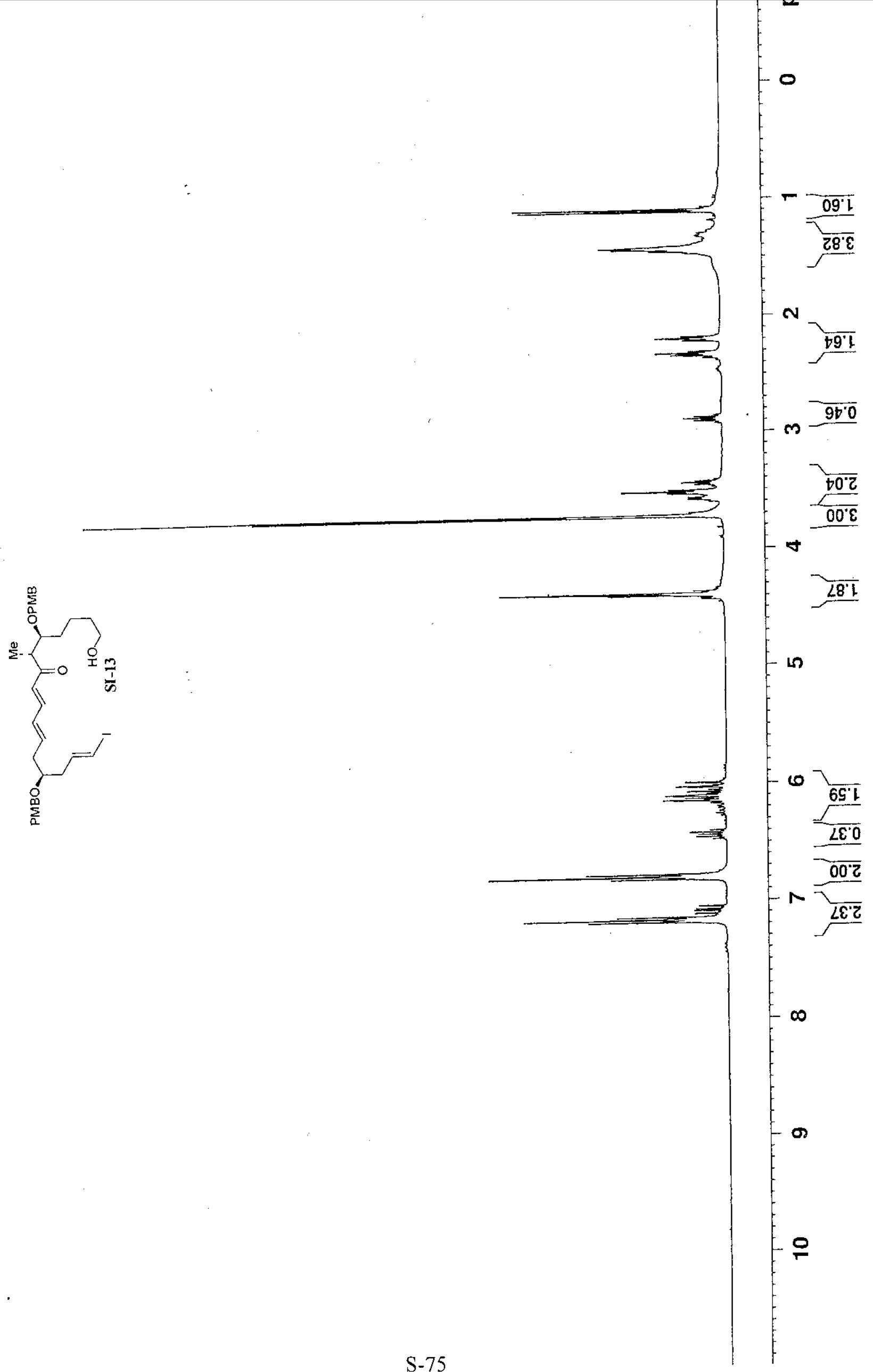




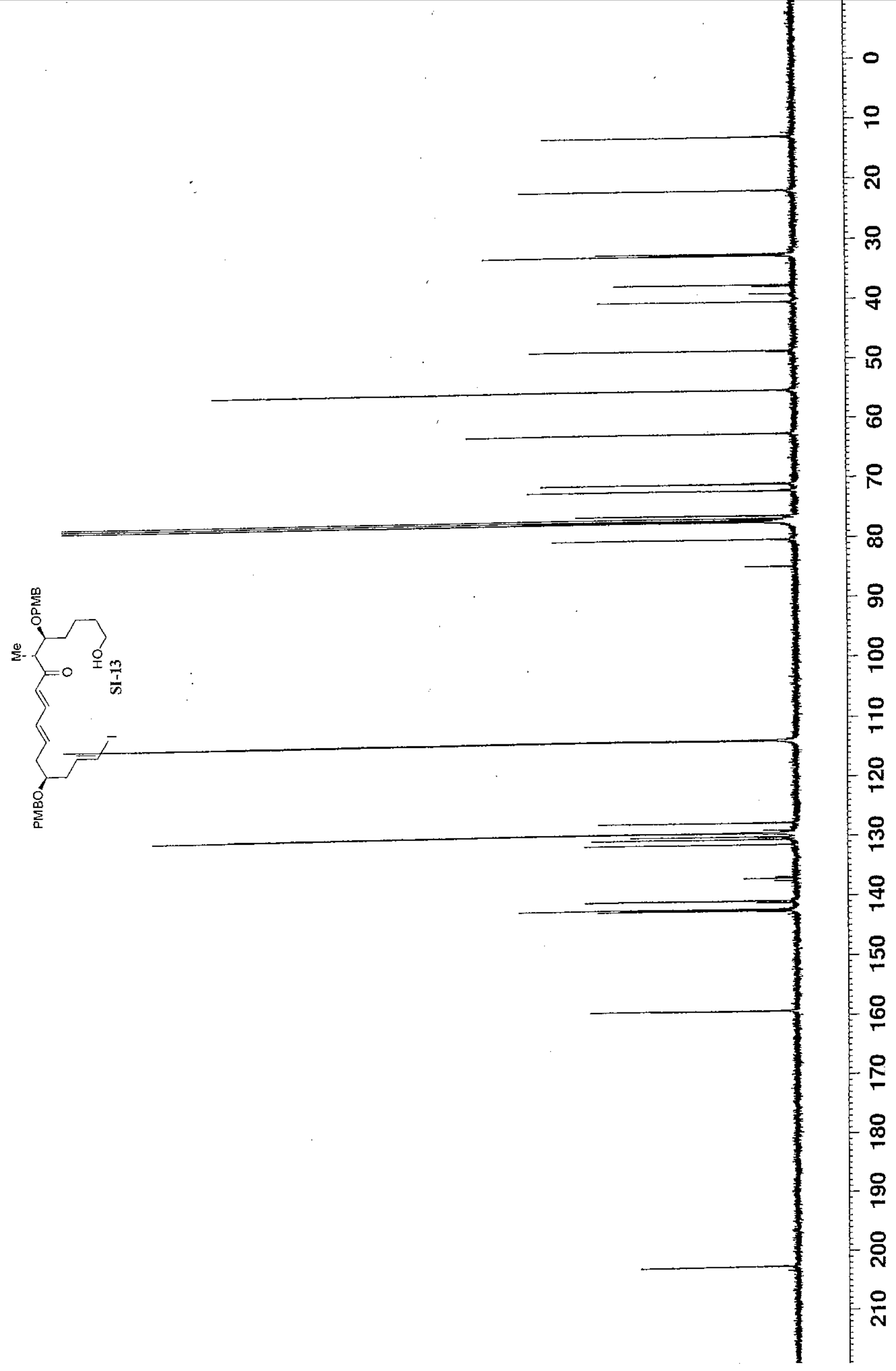

S-76 


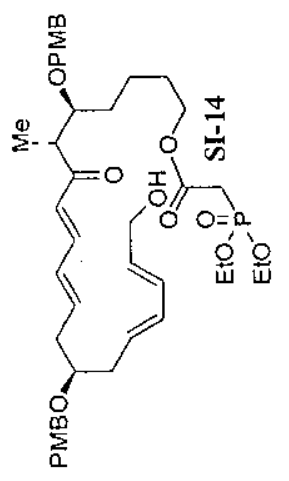




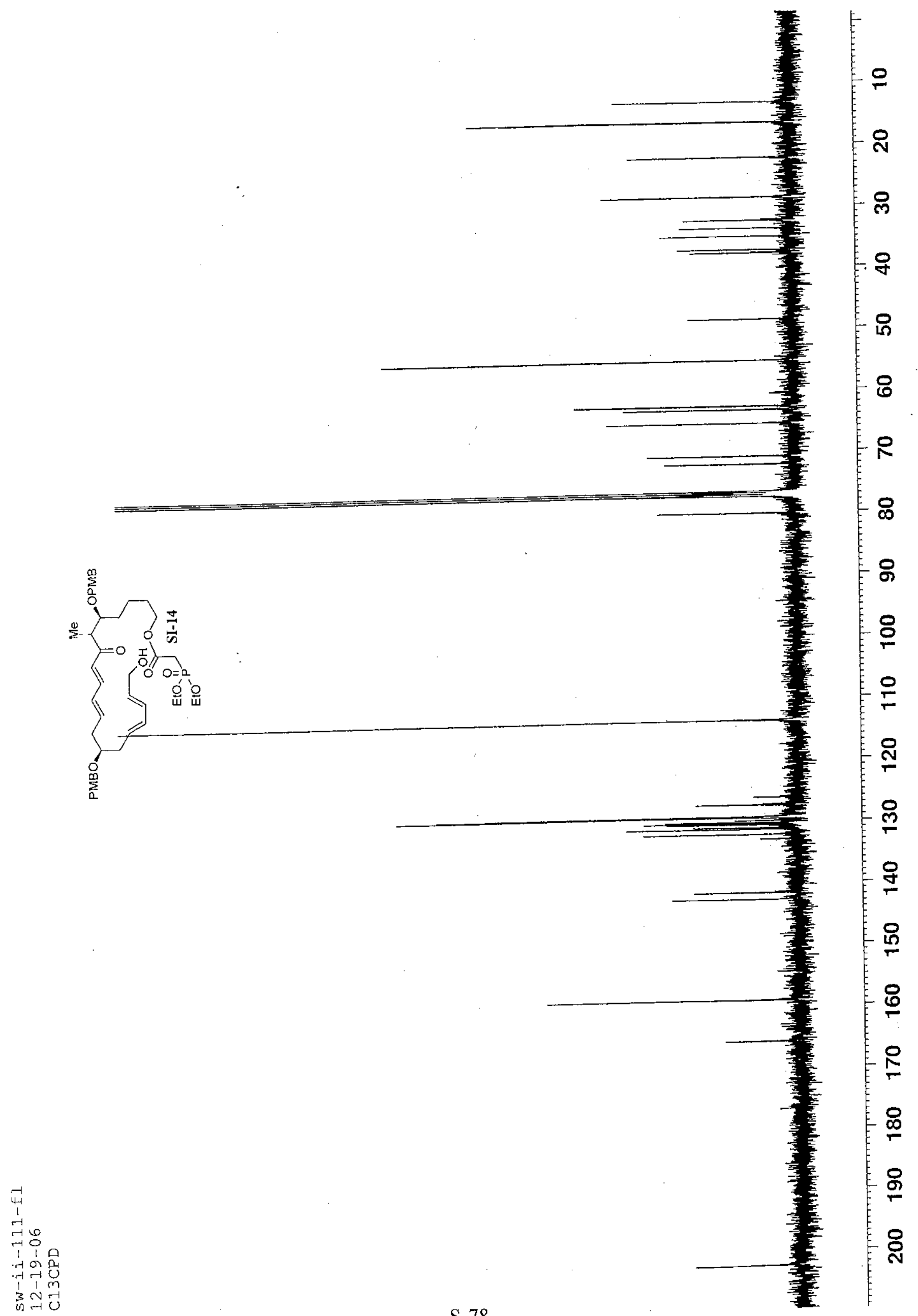

